\title{
Analysis of machining-induced residual stresses of milled aluminum workpieces, their repeatability, and their resulting distortion
}

\author{
Daniel Weber ${ }^{1} \cdot$ Benjamin Kirsch ${ }^{1} \cdot$ Christopher R. Chighizola $^{2}$ - Christopher R. D'Elia ${ }^{2}$ Barbara S. Linke ${ }^{2}$. \\ Michael R. Hill ${ }^{2}$ Jan C. Aurich ${ }^{1}$
}

Received: 15 January 2021 / Accepted: 27 April 2021 / Published online: 22 May 2021

(C) The Author(s) 2021

\begin{abstract}
Machining-induced residual stresses (MIRS) are a main driver for distortion of thin-walled monolithic aluminum workpieces. Before one can develop compensation techniques to minimize distortion, the effect of machining on the MIRS has to be fully understood. This means that not only an investigation of the effect of different process parameters on the MIRS is important. In addition, the repeatability of the MIRS resulting from the same machining condition has to be considered. In past research, statistical confidence of MIRS of machined samples was not focused on. In this paper, the repeatability of the MIRS for different machining modes, consisting of a variation in feed per tooth and cutting speed, is investigated. Multiple hole-drilling measurements within one sample and on different samples, machined with the same parameter set, were part of the investigations. Besides, the effect of two different clamping strategies on the MIRS was investigated. The results show that an overall repeatability for MIRS is given for stable machining (between 16 and 34\% repeatability standard deviation of maximum normal MIRS), whereas instable machining, detected by vibrations in the force signal, has worse repeatability $(54 \%)$ independent of the used clamping strategy. Further experiments, where a 1-mm-thick wafer was removed at the milled surface, show the connection between MIRS and their distortion. A numerical stress analysis reveals that the measured stress data is consistent with machining-induced distortion across and within different machining modes. It was found that more and/or deeper MIRS cause more distortion.
\end{abstract}

Keywords Machining-induced residual stresses $\cdot$ Distortion $\cdot$ Milling aluminum $\cdot$ Finite element method

\section{Introduction}

The surface integrity is an important domain of part quality, especially the part quality of milled monolithic thin-walled aluminum components in the aerospace industries [1]. There is a constant need for improved surface integrity and enhanced functional performance of machined components [2]. Residual stresses (RS) are one attribute of the surface integrity and have a major influence on in-service failures such as corrosion and fatigue life of parts [3]. RS are defined as the internal

Daniel Weber

daniel.weber@mv.uni-kl.de

1 Institute for Manufacturing Technology and Production Systems, Technische Universität Kaiserslautern, Gottlieb-Daimler-Str, D-67663 Kaiserslautern, Germany

2 Department of Mechanical and Aerospace Engineering, University of California, One Shields Avenue, Davis, CA 95616, USA stresses locked in a body, where force and torque equilibrium prevail and no thermal gradients appear [4]. It is known that RS in thin-walled monolithic aluminum parts, where up to $90 \%$ of the initial material is removed, cause distortions. These distortions lead to high costs due to remanufacturing and part rejection [4]. In this context, one must distinguish between two sorts of RS [5]. One sort are the initial bulk residual stresses (IBRS), which exist previous to machining in the blank material. They are caused by processes like heat treatments (e.g., quenching) and appear throughout the entire part-thickness [5]. The second sort are the machining-induced residual stresses (MIRS), which are driven into the material during the machining process. In terms of surface integrity, the MIRS are from greater interest, because their penetration depth is limited to a shallow layer just under the part surface. A typical MIRS profile in a milled aluminum material looks square root shaped $(-\sqrt{-}-)$ with compressive RS near the surface [5].

It is known that different machining parameters and different tool geometries cause different MIRS [5]. Especially the high mechanical loads which occur during machining induce 
a non-uniform plastic deformation on the surface layers of the materials [6]. Typically, those deformations lead to a square rooted shaped compressive residual stress profile, which varies in the maximum residual stress (MaxRS), the depth of it $\left(t_{\mathrm{m}}\right)$, and the penetration depth $\left(t_{\mathrm{p}}\right)$ depending on the machining parameters. The penetration depth is hereby defined as the thickness of the layer containing MIRS. Research investigating the effect of the feed per tooth, cutting speed, width of cut, depth of cut, and tool geometry was conducted in the past. It was found that an increase of the feed per tooth leads to higher MaxRS at greater depths $\left(t_{\mathrm{m}}\right)$ when milling A17449-T7651 samples with end mills and cutters with indexable inserts parallel to feed direction $[7,8]$. The depth $t_{\mathrm{m}}$ increased from $0 \mu \mathrm{m}$ to a maximum of approx. $45 \mu \mathrm{m}$, while the MaxRS increased from approx. $-325 \mathrm{MPa}$ to $-400 \mathrm{MPa}$ for milling with a cemented carbide helical cutter $(d=20 \mathrm{~mm})$ for an increased feed per tooth $f_{\mathrm{z}}$ from $0.05 \mathrm{~mm}$ to $0.30 \mathrm{~mm}\left(a_{\mathrm{p}}=4 \mathrm{~mm}, a_{\mathrm{e}}=20 \mathrm{~mm}\right)$ [7]. The same trend of an increased MaxRS was investigated for milling A17050-T6 with inserts in cutting direction [9] and A17050-T7451 with end mills in feed and cutting direction [10]. In contrast, the investigations of Tang et al. showed no systematic trend of MaxRS and $t_{\mathrm{m}}$ parallel or perpendicular to the feed direction when milling Al7050-T7451 with end mills [11]. The depth $t_{\mathrm{m}}$, e.g., lays between 15 and $20 \mu \mathrm{m}$ and the MaxRS in feed direction does not change significantly (approx. $-80 \mathrm{MPa}$ ) for an increased feed per tooth from 0.1 to $0.2 \mathrm{~mm}$ when milling with a three fluted cemented carbide end mill $(\mathrm{d}=20 \mathrm{~mm}, \mathrm{R}=$ $3 \mathrm{~mm}, a_{\mathrm{p}}=2 \mathrm{~mm}, a_{\mathrm{e}}=10 \mathrm{~mm}, \mathrm{n}=16000 \mathrm{rpm}$ ) [11].

Past research showed that for the variation of cutting speed there is no common effect on the MIRS. Denkena et al. [8] and Perez et al. [3], e.g., observed that increased cutting speeds for milling Al7449-T7651 and Al7050-T7451 respectively, with indexable inserts, lead to an increase in maximum compressive stresses. But in other studies by Denkena et al., the use of helical cutters for different cutting speeds did not influence MaxRS and $t_{\mathrm{m}}$ at all [7]. MaxRS of approx. $-300 \mathrm{MPa}$ was measured at a depth between 30 and $45 \mu \mathrm{m}$ for different $v_{\mathrm{c}}$ between 250 and $1500 \mathrm{~m} / \mathrm{min}$ [7]. Furthermore, decreased compressive RS for an increase of the cutting speed were observed by Tang et al. [11] and Rao et al. [9]. The MaxRS in feed direction was measured to $-120 \mathrm{MPa}(n=4000 \mathrm{rpm})$ and $-90 \mathrm{MPa}(n=16000 \mathrm{rpm})$ [11].

Different researchers found that the MaxRS increased with increasing depth of cut [7, 12]. In contrary for the variation of the width of cut, the highest MaxRS were found for the lowest width of cut [7]. In terms of tool geometry, Denkena et al. showed that an increase of the cutting edge radius [7] and a decrease of the corner radius [8] lead to higher MaxRS.

Above-mentioned research has in common that residual stress measurements per machining state were carried out only on one sample with limited or even no statistical confidence. No repeated measurements on different samples, sharing the same machining condition, were carried out. Furthermore, no shear RS were investigated, although they are an important factor of the distortion caused by the MIRS, hereafter called machining-induced distortion [13]. The present research focuses on the repeatability of MIRS for multiple milled aluminum workpieces, machined with the same machining parameter. Our previous research studied the repeatability of RS measurement techniques (hole-drilling, slotting, $\sin ^{2}(\psi)$ $\mathrm{XRD}, \cos (\alpha) \mathrm{XRD})$ themselves $[13,14]$. It was found that data from hole-drilling (HD) are most consistent with machining-induced distortion for AA7050-T7451 parts and multiple measurements are necessary to describe the MIRS with good statistical confidence. Therefore, the HD technique and three measurements per sample were set as the standard for the present research. In this context, one measurement is defined as the measurement of the entire MIRS depth profile down to a depth of $500 \mu \mathrm{m}$. To identify the repeatability of MIRS resulting from machining under the same condition, three samples were machined for each machining set. Four different machining sets, consisting of a variation in feed per tooth and cutting speed, were investigated to analyze the effect of different machining parameters on the MIRS. Furthermore, the effect of two different clamping strategies, a vise and side clamps, on the MIRS was analyzed. Forces and temperatures were measured during machining. In total, 17 samples were machined and $51 \mathrm{HD}$ depth profiles were conducted. Moreover, distortion experiments, where a 1-mm-thick wafer was removed at the milled surface, were carried out to show the machining-induced distortion. In this context a numerical stress analysis was computed to analyze if the measured holedrilling data are consistent with the measured distortion. The objectives of the present research are summarized as follows:

- Investigation of the repeatability of MIRS for machining multiple samples

- Investigation of the influence of machining parameters on MIRS and their repeatability

- Investigation of the influence of the clamping strategy on the MIRS

- Investigation of machining-induced distortion

\section{Methods}

\subsection{Machining-induced residual stress experiments}

Down milling was carried out on a 5 -axis DMG Mori ${ }^{1}$ DMU $70 \mathrm{CNC}$ machine. Cemented carbide end mills of the type

\footnotetext{
${ }^{1}$ Naming of specific manufacturers is done solely for the sake of completeness and does not necessarily imply an endorsement of the named companies nor that the products are necessarily the best for the purpose.
} 
Table 1 Tool properties

\begin{tabular}{ll}
\hline Tool properties & Kennametal $^{1}$ F3AA1200AWL \\
\hline Type & Regular end mill \\
Diameter & $12 \mathrm{~mm}$ \\
Tool holder & HSK-A 63 \\
Material & Cemented carbide $10 \% \mathrm{Co}, 0.6 \% \mathrm{Cr}, 89.4 \% \mathrm{WC}$ \\
& max. grain size $3 \mu \mathrm{m}$ \\
Number of flutes $z$ & 3 \\
Helix angle & $45^{\circ}$ \\
Cutting edge radius & - \\
Length & $76 \mathrm{~mm}$ \\
Coating & - \\
\hline
\end{tabular}

Kennametal ${ }^{1}$ F3AA1200AWL were used, because it represents a typical tool for machining of aerospace aluminum alloys. The tool properties can be found in Table 1. Aluminum blocks AA7050-T7451 with the dimensions $206 \times 102 \times 28.5 \mathrm{~mm}^{3}$ were face milled on the $206 \times 102 \mathrm{~mm}^{2}$ face. In order to reduce the IBRS, the AA7050-T74 samples come in a stress-relieved condition (T7451) [15], where the IBRS are decreased to magnitudes lower than $20 \mathrm{MPa}$ [16]. The samples were cut from a large slab of stress-relieved aluminum measuring $1250 \times 1250 \times 102 \mathrm{~mm}^{3}$, where six blocks of material $\left(660 \times 206 \times 102 \mathrm{~mm}^{3}\right)$ were saw cut. These blocks were cut again into 15 individual samples $\left(206 \times 102 \times 28.5 \mathrm{~mm}^{3}\right)$.

The feed ( $x$-) direction corresponded to the 206-mm dimension and the orthogonal feed (y-) direction to the $102-\mathrm{mm}$ dimension. The tool movement was along the negative $x$-direction with respect to the sample coordinate system (see Fig. 1). The feed per tooth $f_{\mathrm{z}}$ and the cutting speed $v_{\mathrm{c}}$ were varied. Three different feeds per tooth and two different cutting speeds were investigated, which resulted in four parameter modes (see Table 2). They were selected by prior experiments because they represent different load cases and showed less vibrations and no interference with the eigenfrequency of the set up. The width of cut $a_{\mathrm{e}}$ and depth of cut $a_{\mathrm{p}}$ were kept constant at $4 \mathrm{~mm}$ and $3 \mathrm{~mm}$ respectively, and dry cutting was carried out to only investigate the effect of the cutting parameters on the MIRS without having superpositions due to the cooling.

Two different clamping devices were investigated to show the influence of the clamping strategy on the MIRS. A

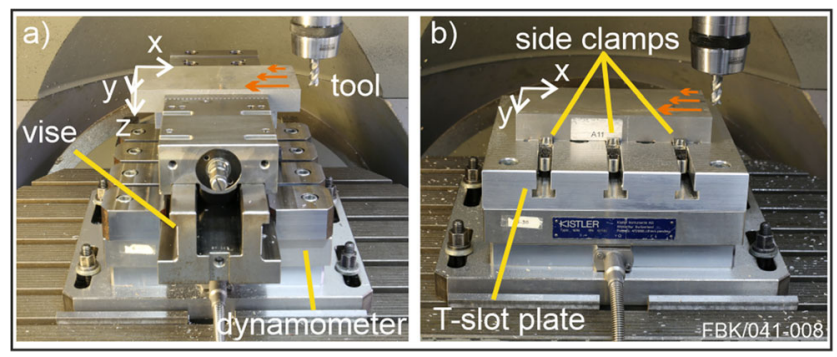

Fig. 1 Experimental setup with vise (a) and side clamps (b) conventional vise and side clamps were used. The jaws of the vise were $125 \mathrm{~mm}$ long and the workpiece was clamped in a way that $5.5 \mathrm{~mm}$ protruded (in z-height) prior to cutting (see Fig. 1a). The clamping force was $15 \mathrm{kN}$. Six side clamps of the type Lenzke ${ }^{1}$ NU10a14 with a maximal nominal clamping force of $7 \mathrm{kN}$ in the $x y$-plane and $3.5 \mathrm{kN}$ in $z$-direction were used. The height of clamping was $5 \mathrm{~mm}$ in $z$-direction (see Fig. 1b).

To investigate the repeatability of MIRS for multiple samples and the influence of different machining modes, twelve machining experiments (three for each mode) were carried out using the vise as a clamping device (see Table 3). In order to investigate the influence of the clamping strategy on the MIRS, five more machining experiments were conducted. One sample each for machining modes 1, 2, and 3 and two samples for mode 4 were machined with the clamping strategy side clamps (see Table 3, where MX stands for machining mode; $\mathbf{A}, \mathbf{B}, \mathbf{C}$ are repetitions machined in vise and $\mathbf{D}, \mathbf{E}$ samples machined in side clamps).

The order of machining the samples was randomly chosen to minimize the influence of tool wear. Furthermore, the tool wear was monitored after machining each sample by a macroscope, so that worn tools were exchanged if wear in the form of corner break outs was qualitatively detected (see Fig. 2).

Plastic deformation, thermal gradients, phase transformation, and their combined effect are the physics which cause MIRS [5]. Therefore, monitoring the thermal and mechanical load during machining is essential for understanding the effect of different machining parameters on the MIRS. The process was monitored by recording forces using a piezoelectric dynamometer (Kistler ${ }^{1}$ Type 9255) with a sampling rate of 15 $\mathrm{kHz}$. One surface layer was removed, which resulted in 25 passes with a constant width of cut of $4 \mathrm{~mm}$. The last $2 \mathrm{~mm}$ was removed in an additional pass. The three orthogonal forces $\left(F_{\mathrm{x}}, F_{\mathrm{y}}, F_{\mathrm{z}}\right)$, where $F_{\mathrm{x}}$ is the force in negative feed direction, $F_{\mathrm{y}}$ in orthogonal feed direction, and $F_{\mathrm{z}}$ is the passive force (see Fig. 1), were analyzed. The forces in every fourth machining pass, beginning with the second, were measured. To compare the forces for the different samples and the different machining modes, the root mean square (RMS) of the force signal of each measured pass was calculated. Run in and run out effects were excluded from the analysis by analyzing $80 \%$ of the force signal. The arithmetic mean and standard deviation over all measured passes per sample, per mode respectively, were computed to compare the force of different samples for each mode, between the different machining modes respectively.

\subsection{Temperature experiments}

The thermal load was determined by temperature measurements. Those were carried out in separate experiments on 
Table 2 Machining parameters cutting speed $v_{\mathrm{c}}$, feed per tooth $f_{\mathrm{z}}$ and resulting feed rate $v_{\mathrm{f}}$, material removal rate $Q_{\mathrm{w}}$, and average chip thickness $h_{\mathrm{m}}$ $[14,17]$

\begin{tabular}{llllll}
\hline Mode & $\begin{array}{l}\text { Cutting speed } \\
v_{\mathrm{c}}(\mathrm{m} / \mathrm{min})\end{array}$ & Feed per tooth $f_{\mathrm{z}}(\mathrm{mm})$ & $\begin{array}{l}\text { Feed rate } v_{\mathrm{f}} \\
(\mathrm{mm} / \mathrm{min})\end{array}$ & $\begin{array}{l}\text { Material removal rate } \\
Q_{\mathrm{w}}\left(\mathrm{mm}^{3} / \mathrm{min}\right)\end{array}$ & $\begin{array}{l}\text { Average chip thickness } \\
h_{\mathrm{m}}(\mathrm{mm})\end{array}$ \\
\hline Mode 1 & 200 & 0.04 & 637 & 7600 & 0.023 \\
Mode 2 & 200 & 0.1 & 1592 & 19100 & 0.058 \\
Mode 3 & 200 & 0.2 & 3183 & 38200 & 0.115 \\
Mode 4 & 450 & 0.04 & 1432 & 17200 & 0.023 \\
\hline
\end{tabular}

smaller AA7050-T7451 samples with the dimension $30 \times 20 \times 9$ $\mathrm{mm}^{3}$ (see Fig. 3). The sample dimensions had to be decreased in comparison to the previous experiments in order to manufacture the thermocouple hole with an accurate depth. The orientation was the same compared to prior experiments. The feed $(x-)$ direction was along the $30-\mathrm{mm}$ dimension. The samples were clamped in the vise with $4 \mathrm{~mm}$ protruding prior to cutting. Thermocouples type $\mathrm{K}$ with a diameter of $1 \mathrm{~mm}$ (1KI10TDT-40-4000MS) were inserted from the bottom side in the middle of the sample. The nominal distance from their end face to the cutting face was $100 \mu \mathrm{m}$. Three samples per mode were machined in random order to exclude tool wear effects. The sampling rate of the temperature measurements was set to $2 \mathrm{kHz}$. The value of the maximum temperature is calculated by the arithmetic mean of 200 temperature values around the total temperature maximum of each sample (range $\pm 0.05 \mathrm{~s})$.

Also, the true distance of the thermocouple face to the newly generated surface was measured after milling via cross-cut-sections (see Fig. 4).

\subsection{MIRS hole-drilling measurements}

The hole-drilling measurements follow ASTM E837-13a [23], implementing fine incremental hole-drilling [24]. A rosette type A strain gage with a circle diameter of $5.13 \mathrm{~mm}$ is bonded directly to the machined surface at the measurement position (see Fig. 5). A hole with an approximate diameter of $2 \mathrm{~mm}$ is cut in an orbital path with a 1.59 -mm-diameter end mill on an electric spindle [14]. At each incremental cut, the

Table 3 Sample overview including machining modes and clamping strategies

\begin{tabular}{lllll}
\hline & Mode 1 & Mode 2 & Mode 3 & Mode 4 \\
\hline Vise & M1A & M2A & M3A & M4A \\
& M1B & M2B & M3B & M4B \\
\multirow{4}{*}{ Side clamps } & M1C & M2C & M3C & M4C \\
& M1D & M2D & M2D & M4D \\
& & & & M4E \\
\hline
\end{tabular}

strain gage measures three components of strain. Following the depth increments in Table 4, a profile of strain versus depth data is produced which is used to compute stress versus depth profiles. Three HD measurements were carried out per sample at the positions I (b), II (b), and III (b) (see Fig. 5).

The analysis of the repeatability of MIRS for multiple samples is done by interpolating the three independent measurements in each sample to the respective depth schedule in Table 4 and calculating the average stress (Avg) and repeatability standard deviation (RSTD) at each depth. The comparison of the MIRS from different machining modes is done similar to the repeatability analysis. This time all independent measurements for each mode are interpolated to the respective depth schedule and the average stress and the RSTD at each depth were calculated. The following characteristics for each RS profile are pointed out and compared to each other in the RS analysis Section 3.3:

- The maximum residual stress (MaxRS) with $\operatorname{MaxRS}_{\mathrm{x}}$ along $x$-direction, MaxRS $_{y}$ along $y$-direction, and MaxRS $_{x y}$ in shear direction is defined as the highest absolute value of RS, which includes compressive (negative) RS as well

- The depth of the MaxRS $t_{\mathrm{m}}\left(t_{\mathrm{mx}}, t_{\mathrm{my}}, t_{\mathrm{mxy}}\right)$
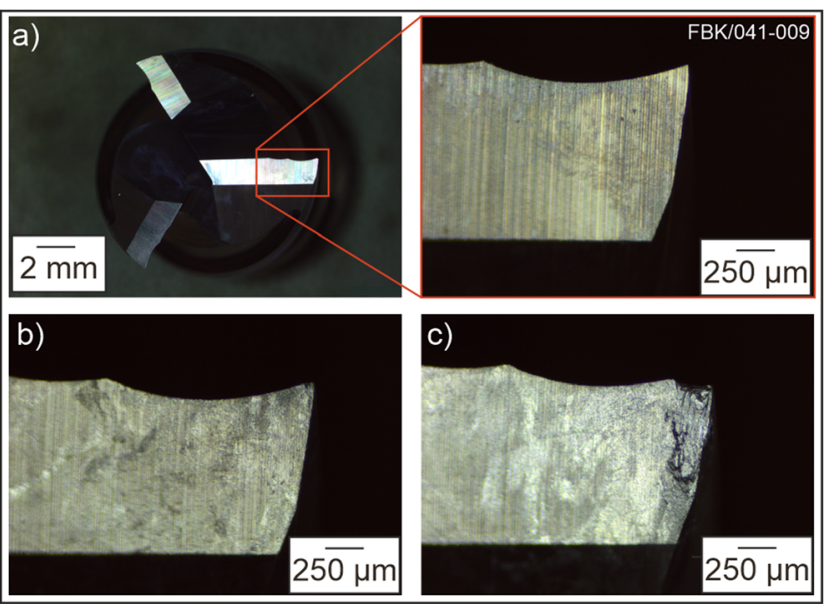

Fig. 2 Macroscopic picture of the end face of a new tool (a), used tool for second use allowed (b), and worn tool, not to be re-used (c) 


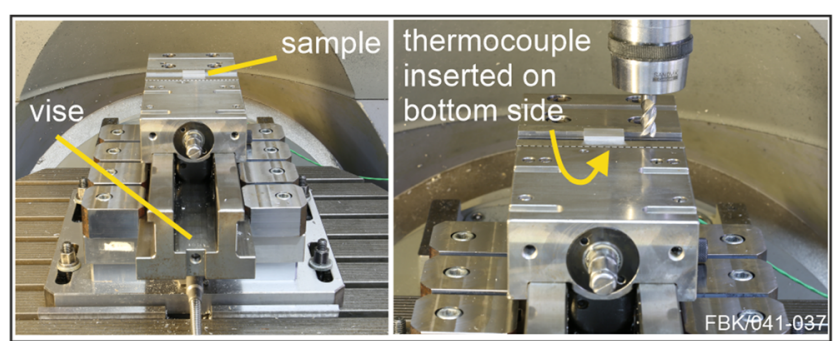

Fig. 3 Experimental set up for temperature measurements

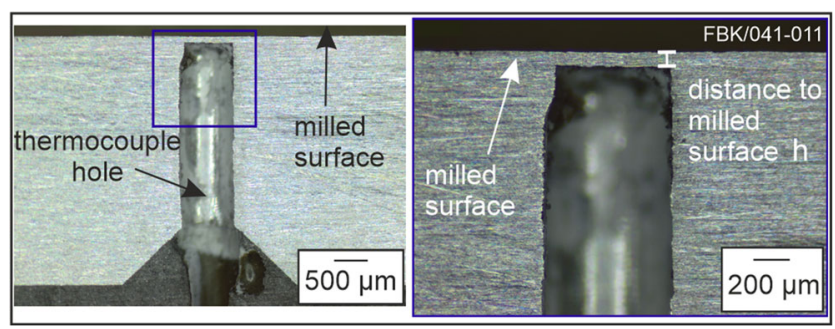

Fig. 4 Macroscopic picture of cross-section of thermocouple hole after milling

- The penetration depth $t_{\mathrm{p}}\left(t_{\mathrm{px}}, t_{\mathrm{py}}, t_{\mathrm{pxy}}\right)$, which is defined as the thickness of the layer containing MIRS and here detected as the depth at which the absolute value of MIRS drops below $20 \mathrm{MPa}$

\subsection{Machining-induced distortion experiments and simulations}

A simple distortion experiment was developed and carried out to study the influence of MIRS on part distortion. Thin wafers were removed from the larger $206 \times 102 \times 28.5 \mathrm{~mm}^{3}$ samples using a wire electric discharge machine (EDM) at one of the two locations marked in Fig. 5 (red squares represent area of wafer). A cube measuring $25 \times 25 \times 28.5 \mathrm{~mm}^{3}$ was first removed from the larger sample. This cube was rotated and a 1-mm-thick wafer measured from the machined surface was removed via wire EDM. The $25 \times 25 \mathrm{~mm}^{2}$ EDM surface was scanned using a laser profilometer at points with $0.2-\mathrm{mm}$ spacing across both $25-\mathrm{mm}$ dimensions to measure differences in in-plane surface height. The measurement points were set $1 \mathrm{~mm}$ away from the edges, which leads to a measurement area of $23 \times 23 \mathrm{~mm}^{2}$. This provided a map of the distorted shape of the wafer which is assumed to be the results of MIRS. The final part distortion was analyzed by first leveling (subtracting fitted polynomial plane of order $1 \times 1$ ), similar to the approach presented by Garcia et al. [18], and then shifting the dataset by the $z$-height of the middle of the wafer, where the minimum was expected (average of $z$ values in the middle of the sample, including all measured data within $0.5 \mathrm{~mm}$ in each $(x-, y$-) direction).

A numerical stress analysis was carried out to check to what extent the MIRS correlate with the wafer distortion. A static, linear elastic finite element model, based on the approach used in [19-21], was set up in ABAQUS ${ }^{1}$. The measured MIRS were implemented as an input and the distortion was calculated, after equilibrium had been set. The geometry was, according to the wafers, a $25 \times 25 \times 1-\mathrm{mm}^{3}$ thin plate (see Fig. 6), where the $z$-direction corresponds to the depth of the MIRS. The MIRS were linearly interpolated over depth at the element centroids and applied as an initial condition (initial condition type $=$ stress, see [27]). For depth smaller than the first measured point, the first measured MIRS was used. For depth greater than the last measured depth, the MIRS were set to $0 \mathrm{MPa}$ (see Fig. 6). The respective information of the depth (z-position) of each element was read in from the ABAQUS ${ }^{1}$ input file via a developed MatLab ${ }^{1}$ script, which also assigned each element the information of the residual stress according to its depth. The mesh consisted of eight-node brick elements (C3D8) with 77,500 elements in total. The in-plane (xy) size of the elements was set to $500 \mu \mathrm{m}$. There were 31 elements in
Fig. 5 Position of hole-drilling and wafer measurements

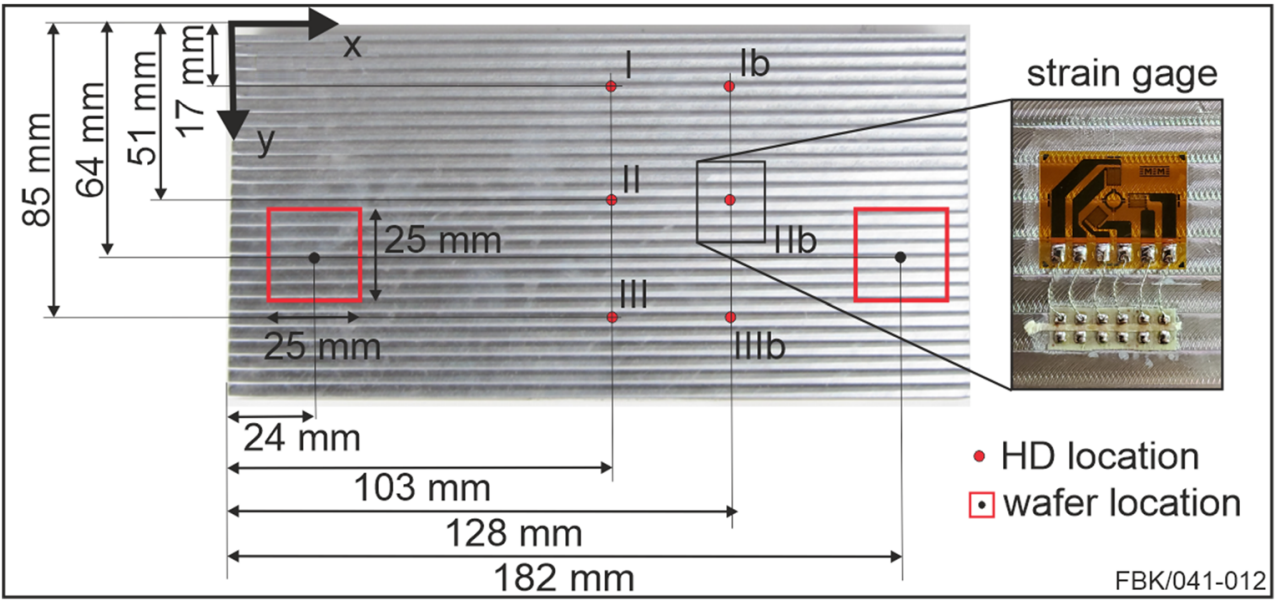


Table 4 Summary of depth increments for hole-drilling measurements [13]

\begin{tabular}{ll}
\hline Increment in mm & Depth in mm \\
\hline 0 & - \\
0.0127 & 0.0127 \\
0.0127 & 0.0254 \\
0.0127 & 0.0381 \\
0.0127 & 0.0508 \\
0.0127 & 0.0635 \\
0.0127 & 0.0762 \\
0.0127 & 0.0889 \\
0.0127 & 0.1016 \\
0.0127 & 0.1143 \\
0.0127 & 0.127 \\
0.0254 & 0.1524 \\
0.0254 & 0.1778 \\
0.0254 & 0.2032 \\
0.0254 & 0.2286 \\
0.0254 & 0.254 \\
0.0254 & 0.2794 \\
0.0508 & 0.3302 \\
0.0508 & 0.381 \\
0.0508 & 0.4318 \\
0.0508 & 0.4826 \\
0.0508 & 0.5334 \\
0.0508 & 0.5842 \\
\hline &
\end{tabular}

$z$-direction with the smallest size of $5 \mu \mathrm{m}$ at the machined surface and bigger elements at the bottom face $(100 \mu \mathrm{m})$ (see Fig. 6), in order to precisely resolve the residual stresses near the surface and still reduce the total number of elements for calculation time reasons. The body was constrained by the 3-2-1 constraint principle, which avoided rigid body motion,

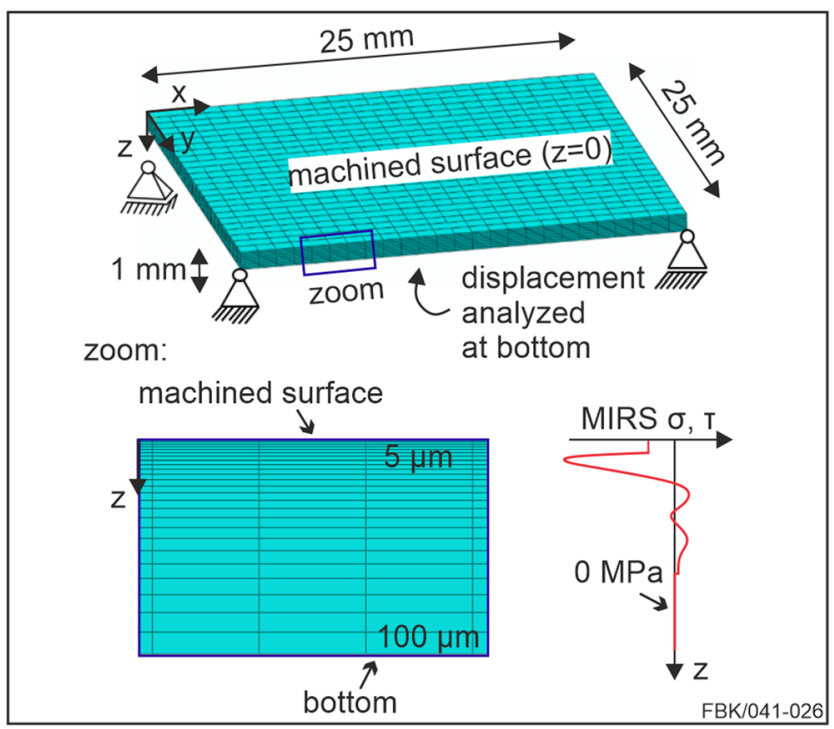

Fig. 6 Finite element model to predict distortion due to MIRS
Table 5 Wafer sample overview

\begin{tabular}{lllll}
\hline & Mode 1 & Mode 2 & Mode 3 & Mode 4 \\
\hline Vise & M1A & M2A & M3B & M4A \\
& M1B & M2C & M3C & M4B \\
\hline
\end{tabular}

but enabled a free distortion of the body [22]. Linear elastic material behavior with a Young's modulus $E$ of 71,700 $\mathrm{MPa}$ and a Poisson ratio $v$ of 0.33 was given. After equilibrium was calculated, the displacement at the bottom was analyzed by leveling and shifting (by $z$-value in the middle of the wafer) the data and then compared to the wafer distortion measured in the experiment.

Two wafers for each mode were investigated to show the distortion within and across different machining modes (see Table 5). In addition, FEM simulations were carried out for all wafers to show the connection between measured MIRS and their distortion.

\section{Results and discussion}

\subsection{Force analysis}

The comparison of the forces of samples machined in the vise show that for all modes, forces in $y$-direction are the highest (see Fig. 7), because this is the main cutting direction. Forces $F_{\mathrm{x}}$ and $F_{\mathrm{z}}$ are much lower than $F_{\mathrm{y}}$. The one-way ANOVA was applied for statistically testing the differences in the means of all samples machined in the vise (for each mode and force component). The null hypothesis states that the means are the same. The $p$-value of each ANOVA test is displayed in Fig. 7 in the respective upper left corner $\left(p_{\mathrm{A}}\right)$. The ANOVA analysis found that the observations support a difference in the mean of all RMS vise forces except M2 $F_{\mathrm{z}}\left(p_{\mathrm{A}}>0.05\right.$ significance level), which highlights that the std of the mean RMS force of each sample is low, while the different mean values differ slightly. Nevertheless, from a physical point of view, the forces within each mode are on a similar level with a maximum variation $\left(1-\mathrm{mean}_{\min } / \mathrm{mean}_{\max }\right)$ by only $20 \%$. Forces $F_{\mathrm{x}}$ of mode 4 are an exception as they scatter more with a maximum variation of $60 \%$ for vise samples. An independent $t$ test was applied for statistically testing the differences in the mean RMS forces for all samples machined in the vise compared to the ones of samples machined in the side clamps for each mode and force component respectively. The null hypothesis states that the means are the same. The $p$-value of each $t$-test is displayed in Fig. 7 in the respective upper right corner $\left(p_{\mathrm{t}}\right)$. The observations support a statistically significant difference except for M3 $F_{\mathrm{y}}, \mathrm{M} 4 F_{\mathrm{x}}$, and M4 $F_{\mathrm{y}}(p>0.05)$. But in general, the forces for samples machined in the side clamps are on a same level compared to the forces of samples 


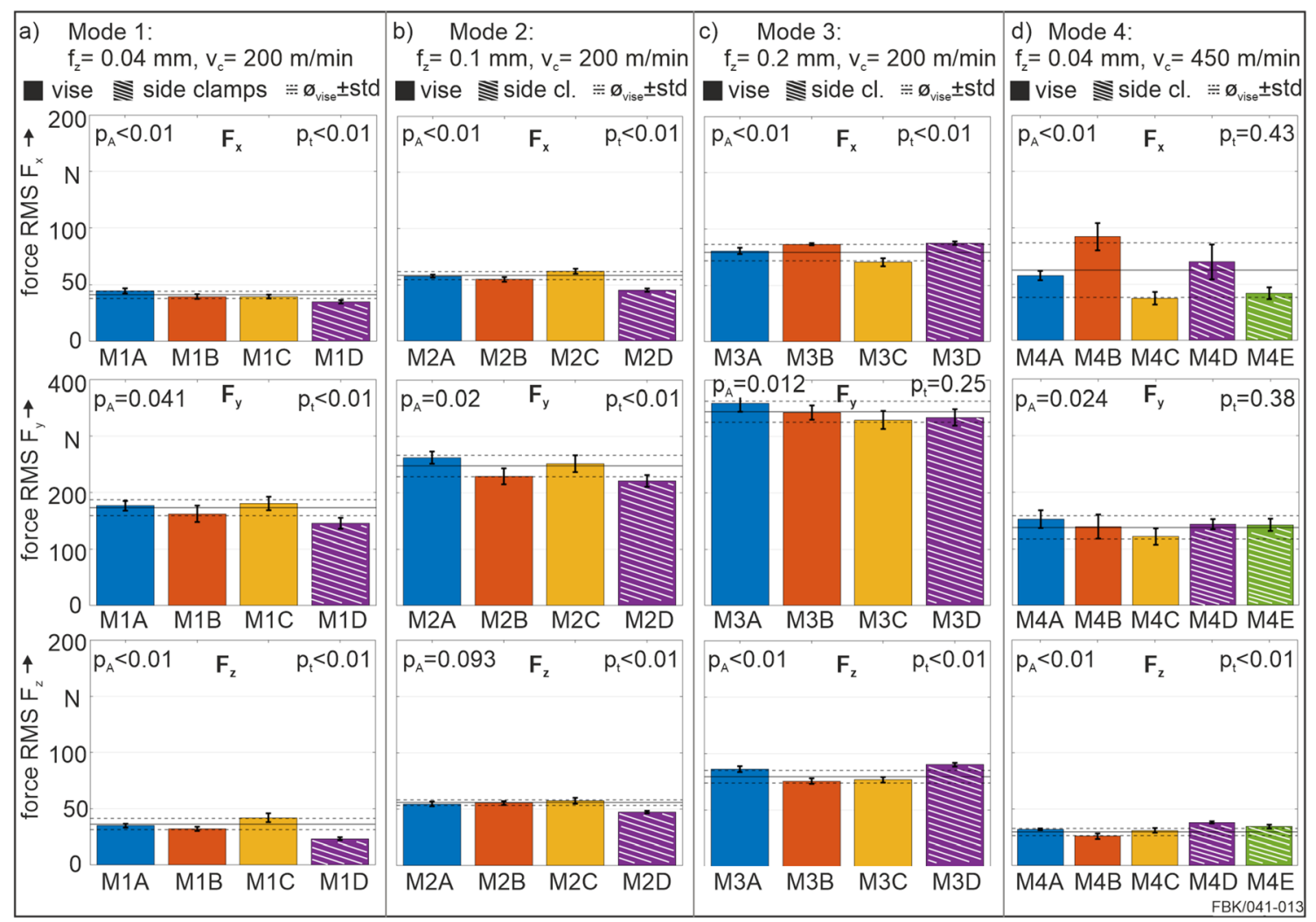

Fig. 7 Mean of RMS forces each sample in $x$-, $y$-, and $z$-direction, error bars represent standard deviation, $p_{\mathrm{A}}$ is the $p$-value of the ANOVA for samples machined in vise for each mode and force component, and $p_{\mathrm{t}}$ is the $p$-value of the independent $t$-test (group I samples machined in vise, group II samples machined in side clamps) for each mode and force component; mind different scales machined in the vise (see Fig. 7): $\mid 1-$ mean $_{\mathrm{sc}(\mathrm{DE})} / \mathrm{mean}_{\mathrm{vise}(\mathrm{ABC})} \mid$ $<22 \%$ for each case. Special trends will be discussed together with the MIRS (see Section 3.3).

The one-way ANOVA was applied for statistically showing that the difference of the mean of the forces of different modes is statistically significant. The null hypothesis states that the means are the same. The $p$-value of each ANOVA test is displayed in Fig. 8 in the respective upper left corner $\left(p_{\mathrm{A}}\right)$. A statistically significant difference is shown by $p_{\mathrm{A}}<$ 0.05 for all force components. The comparison of the forces of different machining modes shows that increasing feed per tooth increases the cutting forces (see Fig. 8). This is due to the greater undeformed chip thickness and material removal rate with increased feed per tooth (see Table 1), which results in a higher energy demand for the plastic deformation of the material and the overcoming of the higher friction [25]. An increase in the cutting speed leads to decreased forces $F_{\mathrm{y}}$ and $F_{\mathrm{z}}$, and increased $F_{\mathrm{x}}$ due to the higher feed rate (compare mode 1 to mode 4 in Fig. 8).

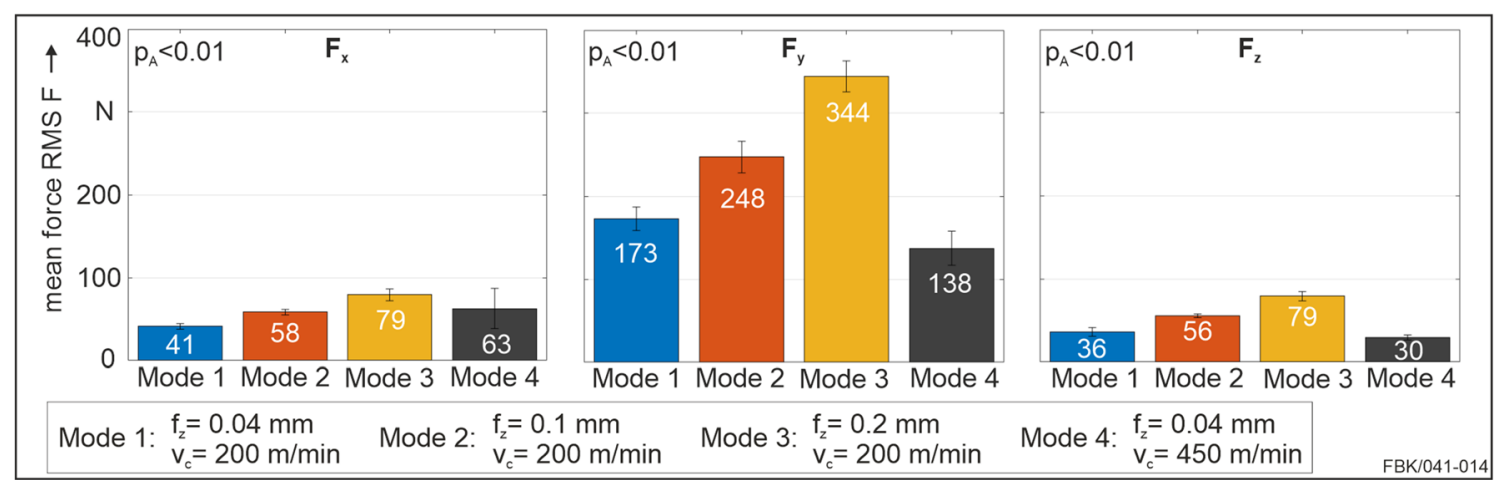

Fig. 8 Inter mode comparison of mean of RMS forces in $x$-, $y$-, and $z$-direction for clamping with a vise, error bars represent standard deviation, $p_{\mathrm{A}}$ is the $p$-value of the ANOVA 


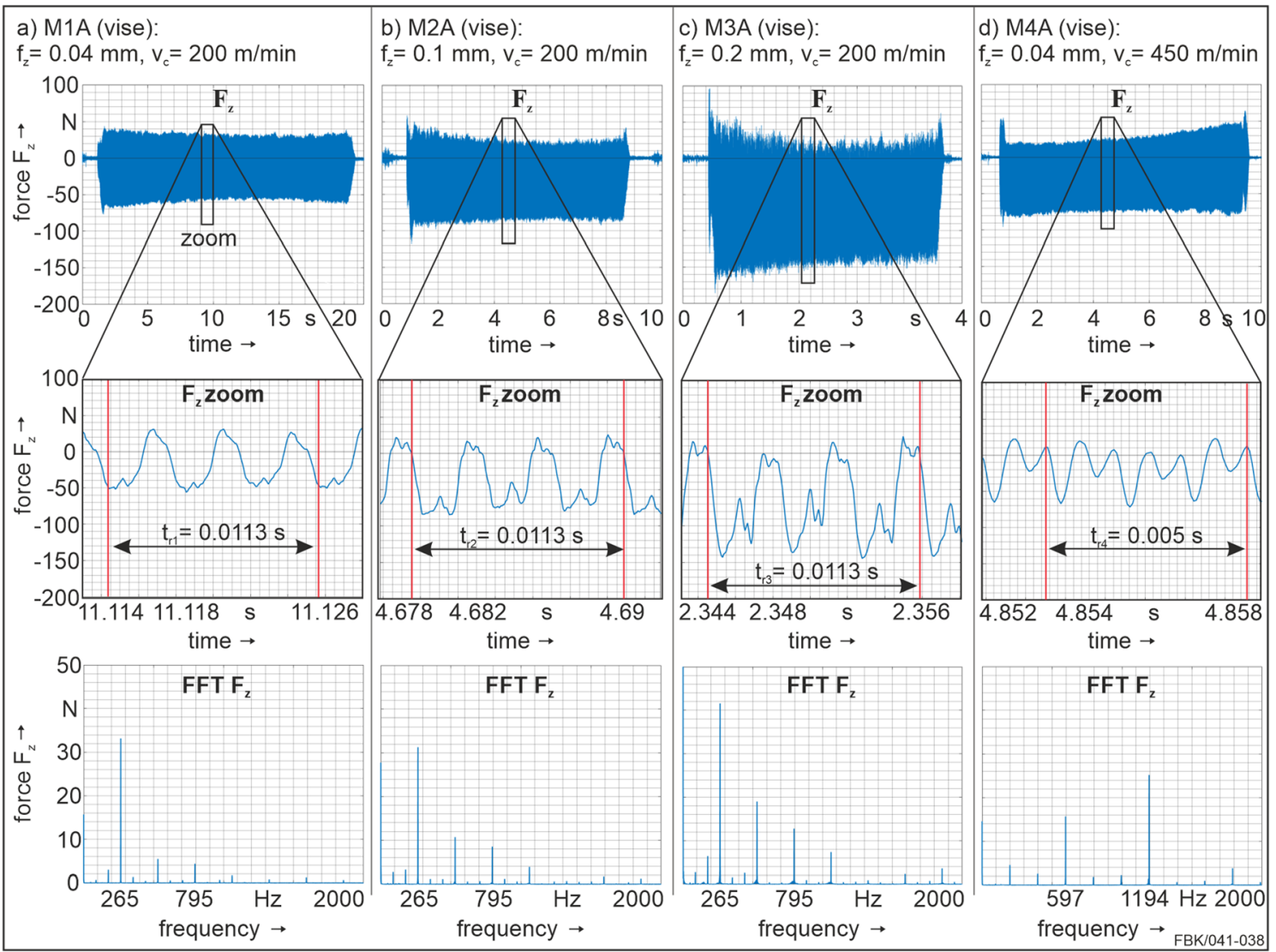

Fig. 9 Force signals $F_{\mathrm{z}}$ and FFT for pass 14 of one vise sample per mode

Figure 9 presents a detailed look on the force signals in the $z$-direction. The entire force signal $F_{\mathrm{z}}$ of pass number 14 is shown for one sample of each mode (M1A, M2A, M3A, $\mathrm{M} 4 \mathrm{~A}$ ) machined in the vise. The samples and their force signals are representative for all samples and passes machined in the vise for the respective mode. Furthermore, a zoomed view, where one rotation of the tool can be traced, and the fast Fourier transformation (FFT) of the force signal, to highlight dominating frequencies during cutting, are shown. It can be seen that due to the given width of cut $\left(a_{\mathrm{e}}=4 \mathrm{~mm}\right)$ and the tool diameter $(d=12 \mathrm{~mm})$, only one flute per time is engaged with the material (tool has 3 flutes). Due to the tool geometry, the tool is primarily pulling the material in negative $z$-direction (see Fig. 1). The cutting edge frequency $f_{\mathrm{c}}$ is here defined as

Table 6 Spindle speed, time per rotation, and cutting edge frequency for all modes

\begin{tabular}{lllll}
\hline & Mode 1 & Mode 2 & Mode 3 & Mode 4 \\
\hline Spindle speed $n(\operatorname{rot} / \mathrm{min})$ & 5305 & 5305 & 5305 & 11937 \\
Duration per rotation $t_{\mathrm{r}}(\mathrm{s})$ & 0.0113 & 0.0113 & 0.0113 & 0.005 \\
Cutting edge frequency $f_{\mathrm{c}}(\mathrm{Hz})$ & 265 & 265 & 265 & 597 \\
$f_{\mathrm{c}}=1 / t_{\mathrm{r}} \cdot 3$ & & & & \\
\hline
\end{tabular}

the frequency of the initial contact of each flute with the material $\left(f_{\mathrm{c}}=1 / t_{\mathrm{r}} \cdot z\right.$, where $z$ represents the number of flutes and $t_{\mathrm{r}}$ the time per rotation). The time per rotation $t_{\mathrm{r}}$ and the cutting edge frequency $f_{\mathrm{c}}$ for each mode are shown in Table 6 . The FFT in Fig. 9 shows that for modes 1,2, and 3, the dominating frequency is the cutting edge frequency $(265 \mathrm{~Hz})$. The FFT of mode 4 force signal reveals that here the dominating frequency is the double of $f_{\mathrm{c}}$ of mode $4(1194 \mathrm{~Hz})$. This indicates that mode 4 shows the most vibrations and could be described as unstable machining.

Figure 10 shows the forces $F_{\mathrm{z}}$ and their FFT for the samples machined in the side clamps M1D, M2D, M3D, and M4D. In general, the force signal looks the same as previously discussed for the samples machined in the vise. But all forces contain more scatter (more higher frequencies of small magnitude) compared to the samples machined in the vise. The amplitudes of the forces for the cutting edge frequency are lower compared to the samples machined in the vise. But for mode 4, the same trend as previously discussed occurs. Only mode 4 has its highest force amplitude at the double cutting edge frequency $(1194 \mathrm{~Hz})$. Modes 1, 2, and 3 have their highest amplitude at their cutting edge frequency $(265 \mathrm{~Hz})$. This indicates that vibrations for mode 4 are independent of the investigated clamping strategy. 


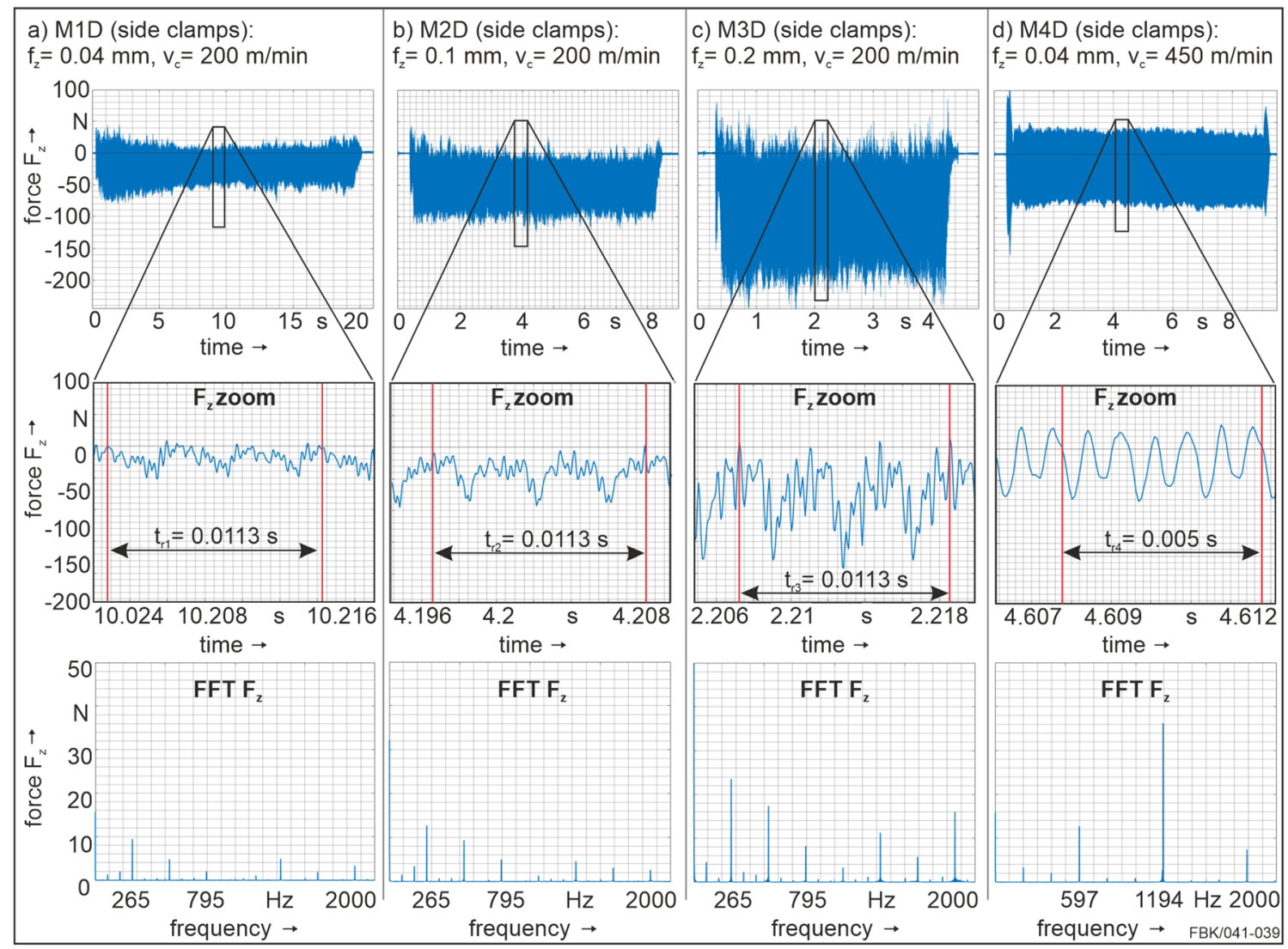

Fig. 10 Force signals $F_{\mathrm{z}}$ and FFT for pass 14 of side clamp sample for each mode

\subsection{Temperature analysis}

The maximum temperature is reached shortly after the tool was moved over the thermocouple. Figure 11a shows the average maximum temperature for each mode ( 3 measurements per mode). All temperatures at a depth of approximately $100 \mu \mathrm{m}$ are on a low level and lie in a range between 30 and $55^{\circ} \mathrm{C}$ (see Fig. 11). The actual distance of the thermocouple face to the surface varies and lays in the range of 75 to 125 $\mu \mathrm{m}$, but has almost no effect on the measured temperatures

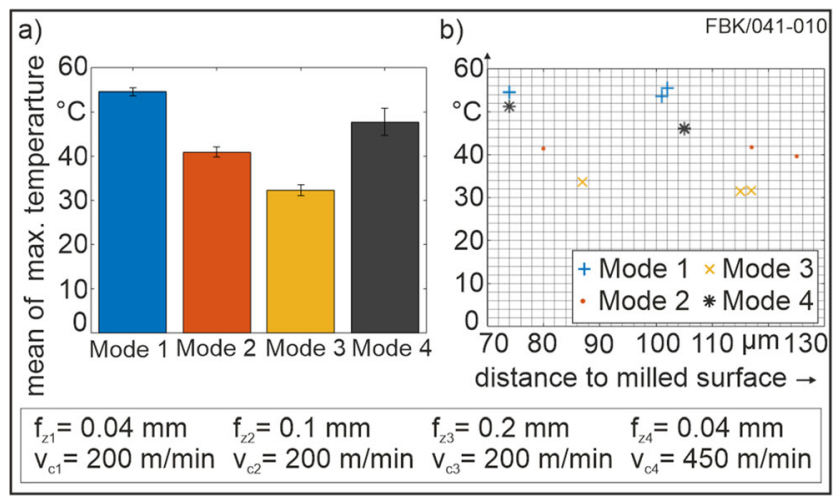

Fig. 11 Mean of maximum temperature per mode (a) and temperature over distance to milled surface distribution (b) (see Fig. 11b). The highest temperatures were recorded for mode 1, with lowest feed. An increase in feed per tooth (mode $1<$ mode $2<$ mode 3 ) leads to a decrease in temperatures that occur at a depth of 80 to $120 \mu \mathrm{m}$ underneath the cutting surface. Higher cutting speeds (with constant feed per tooth) result in a slight decrease in temperatures at a depth of around $100 \mu \mathrm{m}$, compare mode 1 and mode 4. The reason for this effect is that for the given machining parameter mode 1 , the tool moves slower and the sample heats up for a longer time period. Therefore, mode 1 with the lowest feed rate results in the highest temperatures. A comparison of mode 2 and mode 4 (which have similar feed rate-see Table 2) shows that mode 4 (higher cutting speed) results in higher temperatures, which can be explained by the higher amount of friction and shearing events per second for the higher cutting speed.

\subsection{Machining-induced residual stress analysis}

Investigations on the MIRS are divided in following sections:

- MIRS repeatability within one sample — leads to increased understanding of measurement process and variability of MIRS within a single sample 


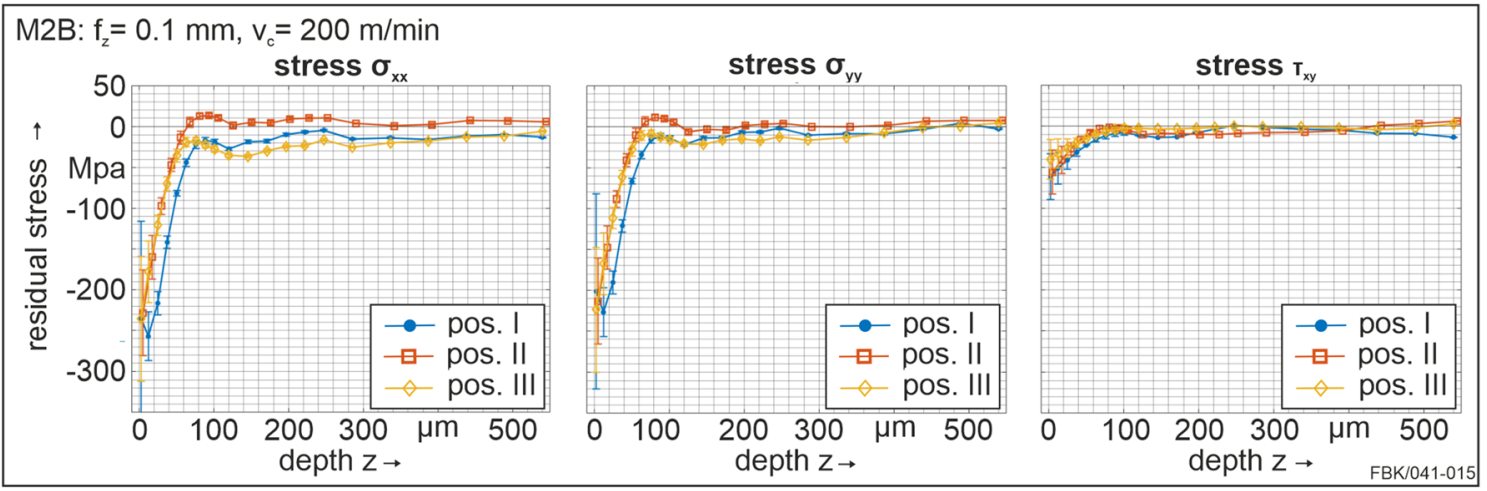

Fig. 12 MIRS measurements on M2B, error bars represent HD measurements uncertainty

- MIRS repeatability of multiple samples sharing same machining condition-leads to increased understanding of MIRS consistency among different samples

- Comparison of MIRS from different machining modesleads to increased understanding of influence of machining parameters on MIRS

- Comparison of MIRS from different clamping strategies-leads to increased understanding of influence of clamping on MIRS

\subsubsection{Machining-induced residual stress repeatability within one sample}

The following discussion is based on measurements on M2B (mode 2), which exhibits a representative RS introduced by milling found across all four modes. Figure 12 shows three RS measurements on M2B, measured at positions I, II, and III. Overall, the three measurements agree well. They show similar stress profiles with compressive residual stresses near the surface and similar penetration depth $t_{\mathrm{p}}$. A high precision is given for two out of three measurements (pos. II and III) for depths deeper than $\sim 20 \mu \mathrm{m}$. Position I shows slightly deeper stresses than positions II and III. In general, the first measured points at a depth smaller than $20 \mu \mathrm{m}$ show a difference in the magnitude of normal and shear residual stress. This is a result of the uncertainty of the measurement technique hole-drilling itself, which is indicated by the error bars in Fig. 12. The holedrilling technique has the highest uncertainty at the first measured shallow depth (for more information, see [13]).

M2B position II picks up tensile stresses in $x$ - and $y$-direction for depths greater than $80 \mu \mathrm{m}$. These are the left-over IBRS after the stress relief process in the middle of the bulk. Position I and position III show compressive stresses at those depths according to their position closer to the edges.

\subsubsection{Machining-induced residual stress repeatability of multiple samples sharing the same machining condition}

Mode 1 All three mode 1 measurements (M1A, M1B, M1C) show a square root-shaped profile for all three stress components $\sigma_{\mathrm{xx}}, \sigma_{\mathrm{yy}}$, and $\tau_{\mathrm{xy}}$, except that the MaxRS exist at the shallowest depth, so that $t_{\mathrm{m}}$ is very small (see Fig. 13). The normal stresses $\sigma_{\mathrm{xx}}$ and $\sigma_{\mathrm{yy}}$ are similar in their magnitude. Shear stresses are smaller. M1A and M1C are highly repeatable. Almost all interpolated stresses are within the standard deviation of each other. The MaxRS is about $-125 \pm 34 \mathrm{MPa}$ (M1A) and $-146 \pm 5 \mathrm{MPa}$ (M1C) in $x$-direction, and -141 $\pm 35 \mathrm{MPa}(\mathrm{M} 1 \mathrm{~A})$ and $-137 \pm 19 \mathrm{MPa}(\mathrm{M} 1 \mathrm{C})$ in $y$-direction. Their penetration depth $t_{\mathrm{p}}$ is at about $60 \mu \mathrm{m}$ for $\sigma_{\mathrm{xx}}$ and $\sigma_{\mathrm{yy}}$. In shear direction, their $\mathrm{MaxRS}_{\mathrm{xy}}$ is $-43 \pm 7 \mathrm{MPa}$ with a penetration depth of about $25 \mu \mathrm{m}$. The stress profile of M1B is

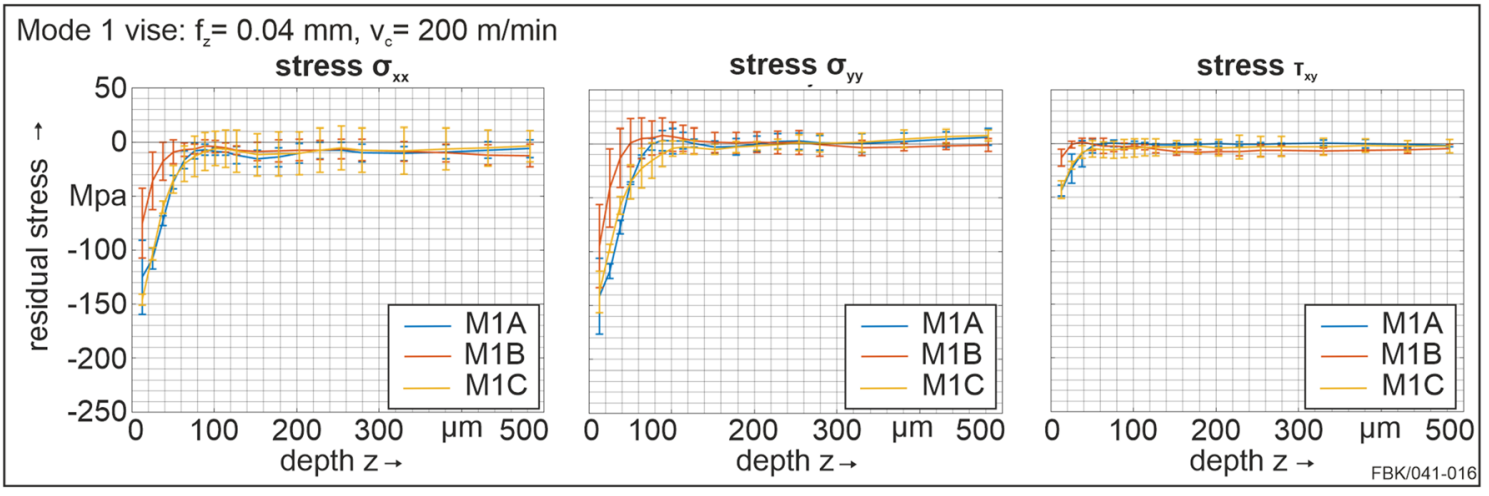

Fig. 13 MIRS mode 1 vise (M1A, M1B, M1C), error bars represent RSTD 


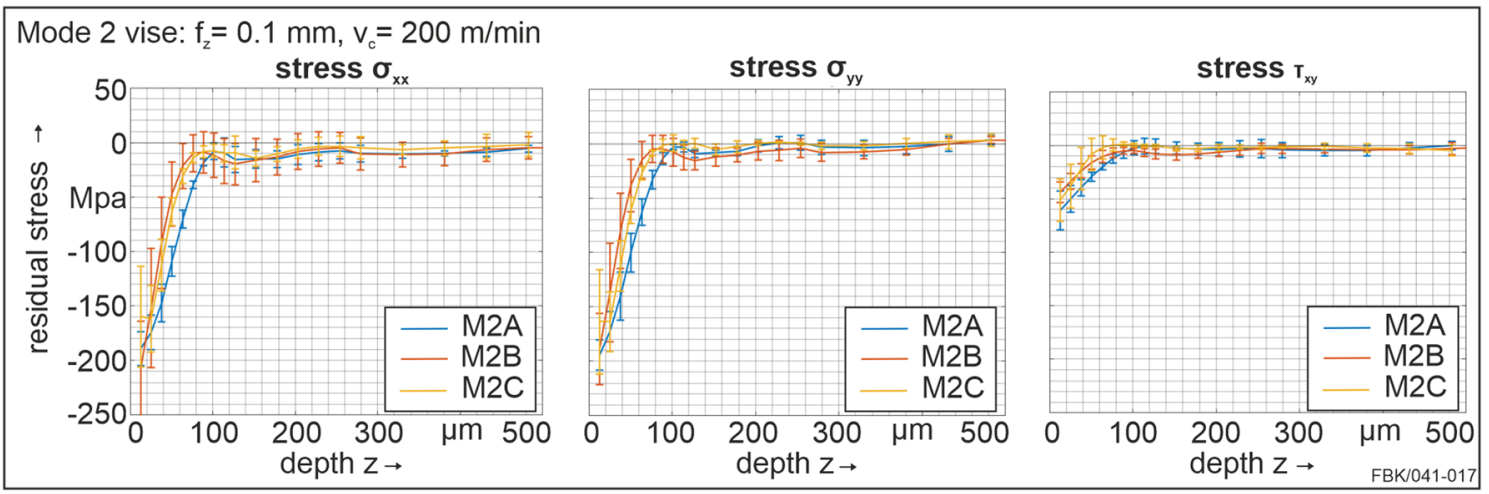

Fig. 14 MIRS mode 2 vise (M2A, M2B, M2C), error bars represent RSTD

similar, but in general shallower with less MaxRS ( -75 $\pm 32 \mathrm{MPa}$ in $x$-direction and $-95 \pm 39 \mathrm{MPa}$ in $y$-direction). The penetration depth is also lower compared to M1A and M1C at about $35 \mu \mathrm{m}$ (normal stresses). The shear stress profile is lower than $20 \mathrm{MPa}$ with the $\mathrm{MaxRS}_{\mathrm{xy}}(-13 \pm 8 \mathrm{MPa})$ at the first depth. A comparison of the forces shows the same trend for $F_{\mathrm{y}}$ and $F_{\mathrm{z}}$ (see Fig. 7). $F_{\mathrm{y}}$ and $F_{\mathrm{z}}$ of M1B are smaller than those of M1A and M1C. This trend does not show up for $F_{\mathrm{x}}$.

Mode 2 Similar to mode 1, M2A and M2B stress profiles show negative RS profiles for all three stress components $\sigma_{\mathrm{xx}}, \sigma_{\mathrm{yy}}$, and $\tau_{\mathrm{xy}}$ with the MaxRS at the first measured depth (see Fig. 14). M2C has their normal MaxRS at the second interpolated depth. Besides that, M2B and M2C are highly repeatable; almost all interpolated stresses are within each other's standard deviation. M2A has a similar stress profile with higher stresses at depths from 50 to $76 \mu \mathrm{m}$. The normal MaxRS are about $-162 \pm 31 \mathrm{MPa}(\mathrm{M} 2 \mathrm{C}),-189 \pm 16 \mathrm{MPa}$ (M2A), and $-207 \pm 43 \mathrm{MPa}(\mathrm{M} 2 \mathrm{~B})$ in $x$-direction, and -164 $\pm 28 \mathrm{MPa}(\mathrm{M} 2 \mathrm{C}),-195 \pm 14 \mathrm{MPa}(\mathrm{M} 2 \mathrm{~A})$, and $-189 \pm 33 \mathrm{MPa}$ (M2B) in $y$-direction. The penetration depth $t_{\mathrm{p}}$ of the normal stresses is at about $65 \mu \mathrm{m}$ (M2B, M2C) and $85 \mu \mathrm{m}$ (M2A). The MaxRS $\mathrm{xy}_{\mathrm{x}}$ is $-44 \pm 10 \mathrm{MPa}(\mathrm{M} 2 \mathrm{~B}),-51 \pm 20 \mathrm{MPa}(\mathrm{M} 2 \mathrm{C})$, and $-61 \pm 18 \mathrm{MPa}(\mathrm{M} 2 \mathrm{~A})$ with $t_{\mathrm{p}}$ in shear direction at $40 \mu \mathrm{m}$ (M2B, M2C) and $64 \mu \mathrm{m}(\mathrm{M} 2 \mathrm{~A})$. A comparison of the forces shows that $F_{\mathrm{y}}$ is also the biggest for M2A. This trend does not follow for $F_{\mathrm{z}}$ and $F_{\mathrm{x}}$.

Mode 3 The stress profiles of mode 3 samples show a typical square root shape with a pronounced MaxRS for all three samples at greater depths (see Fig. 15). The normal MaxRS is about $-103 \pm 32 \mathrm{MPa}(\mathrm{M} 3 \mathrm{~B}),-148 \pm 36 \mathrm{MPa}(\mathrm{M} 3 \mathrm{C})$, and $-145 \pm 33 \mathrm{MPa}(\mathrm{M} 3 \mathrm{~A})$ in $x$-direction, and $-124 \pm 25 \mathrm{MPa}$ (M3B), $-165 \pm 39 \mathrm{MPa}(\mathrm{M} 3 \mathrm{C})$, and $-127 \pm 26 \mathrm{MPa}(\mathrm{M} 3 \mathrm{~A})$ in $y$-direction. M3A and M3B show also a pronounced square root shape profile of the shear stress. MaxRS $\mathrm{xy}_{\mathrm{xy}}$ is -47 $\pm 12 \mathrm{MPa}$ (M3B), $-55 \pm 12 \mathrm{MPa}(\mathrm{M} 3 \mathrm{C})$, and $-46 \pm 13 \mathrm{MPa}$ (M3A). The depth of the normal MaxRS is about $64 \mu \mathrm{m}$ (M3B), $51 \mu \mathrm{m}$ (M3A, M3C $x$-direction), and $38 \mu \mathrm{m}$ (M3C $y$-direction). The depth of the $\mathrm{MaxRS}_{\mathrm{xy}}$ is at $38 \mu \mathrm{m}$ (M3A, $\mathrm{M} 3 \mathrm{~B})$ and $25 \mu \mathrm{m}(\mathrm{M} 3 \mathrm{C})$. The penetration depth is about the same for the normal stresses $(180 \mu \mathrm{m})$ and in shear direction $90 \mu \mathrm{m}(\mathrm{M} 3 \mathrm{~B}, \mathrm{M} 3 \mathrm{C})$ and $140 \mu \mathrm{m}(\mathrm{M} 3 \mathrm{~A})$ respectively. M3B shows the smallest force $F_{\mathrm{z}}$. Aside from that, there is no trend or link to the stresses visible.

Mode 4 The normal stress profiles of mode 4 samples vary (see Fig. 16) more than for the other modes. RS of M4A and M4C have their MaxRS at the first interpolated depth. The MaxRS of M4B is at the second interpolated depth in $x$ - and

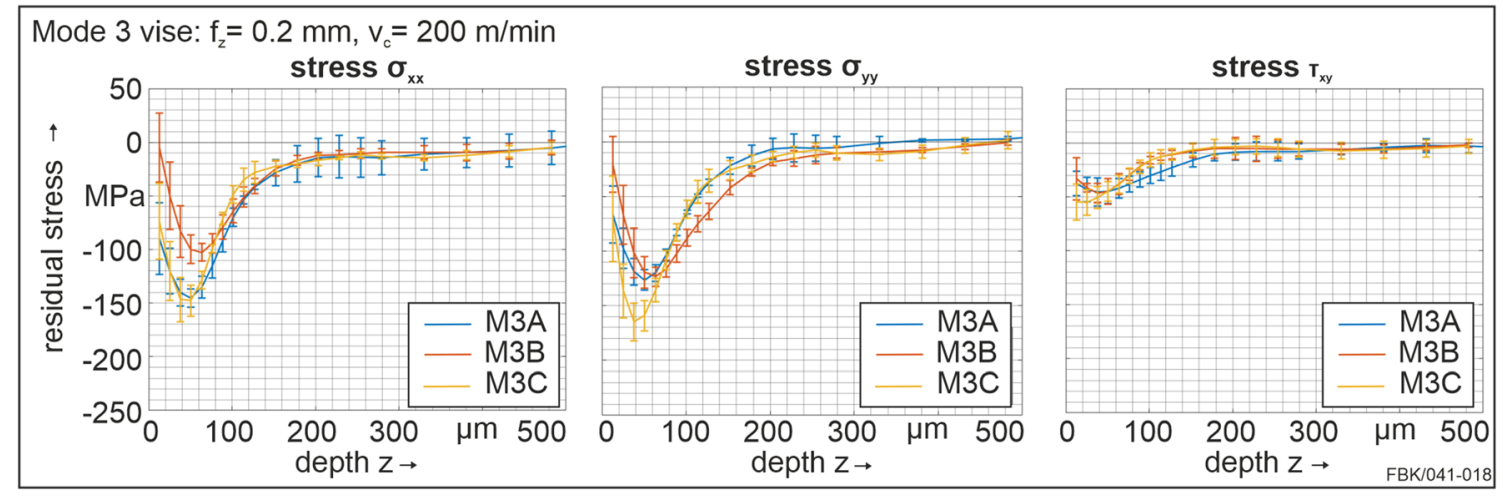

Fig. 15 MIRS mode 3 vise (M3A, M3B, M3C), error bars represent RSTD 


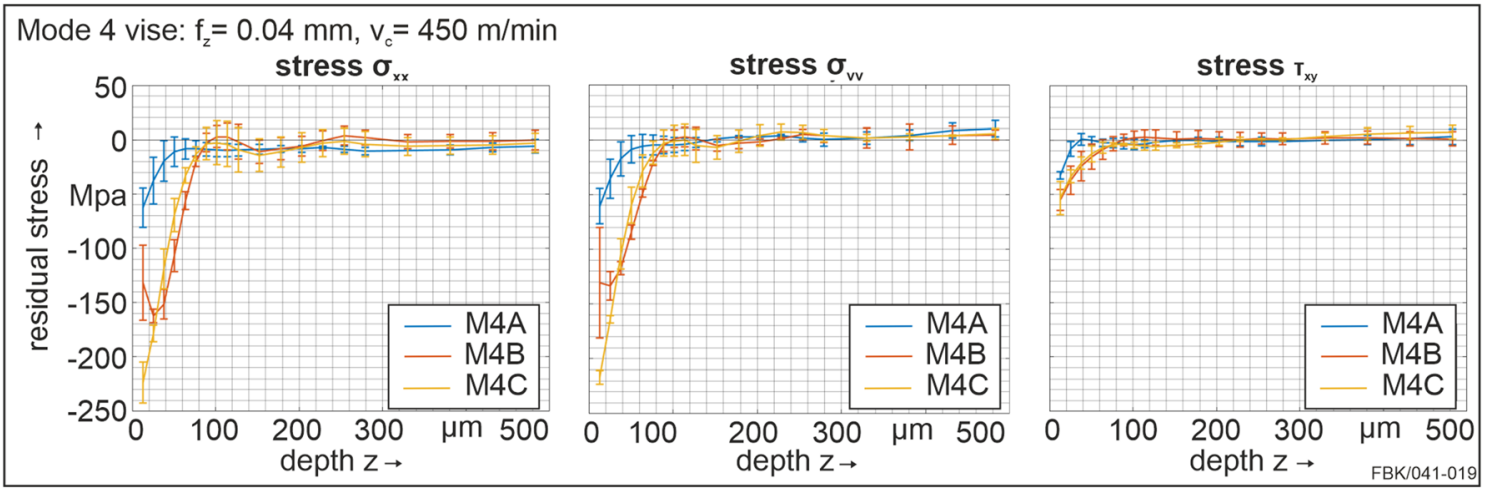

Fig. 16 MIRS mode 4 vise (M4A, M4B, M4C), error bars represent RSTD

$y$-direction. But it should be considered that the standard deviation of the first interpolated depth is relatively high (35 and $50 \mathrm{MPa}$ ). The magnitude of MaxRS varies more than for the other modes: $-224 \pm 19 \mathrm{MPa}$ (M4C), $-162 \pm 35 \mathrm{MPa}$ (M4B), $-63 \pm 19 \mathrm{MPa}(\mathrm{M} 4 \mathrm{~A})$ in $x$-direction and $-217 \pm 6 \mathrm{MPa}(\mathrm{M} 4 \mathrm{C})$, $-134 \pm 13 \mathrm{MPa}(\mathrm{M} 4 \mathrm{~B}),-61 \pm 16 \mathrm{MPa}(\mathrm{M} 4 \mathrm{~A})$ in $y$-direction. From greater depths $(30 \mu \mathrm{m})$ on, M4B and M4C normal RS profiles are similar with a penetration depth of $75 \mu \mathrm{m}$. M4A is shallower with a penetration depth of $40 \mu \mathrm{m}$. The shear stresses of M4C and M4B are repeatable with MaxRS $\mathrm{xy}_{\mathrm{xy}}-54$ $\pm 15 \mathrm{MPa}$ at the first measured depth and a penetration depth of $40 \mu \mathrm{m}$. The shear stress profile of M4A is also shallower with smaller MaxRS $\mathrm{xy}_{\mathrm{xy}}(-33 \pm 3 \mathrm{MPa})$ and $t_{\mathrm{pxy}} 20 \mu \mathrm{m}$. There can be no link or trend to the magnitude of measured forces drawn. As already mentioned in Section 3.1, a closer look at the force signals reveals that in $z$-direction an oscillating behavior is visible. The FFT shows its highest peak for the double cutting edge frequency (see Fig. 9). These vibrations may be the reason for the described differences in RS profiles.

In summary, the comparison of the different samples sharing the same machining mode shows that there is a repeatability to a certain amount present, where mode 4 shows the highest variation. It has to be considered that two out of three profiles for modes 1 and 2 are highly repeatable, but one profile differs slightly in the form of a shallower, deeper, respectively, stress profile. Variation within the different machining modes is quantified in the next section (Section 3.3.3). Furthermore, wafer experiments will highlight if the mentioned differences in MIRS also result in different distortions (see Section 3.4).

\subsubsection{Comparison of machining-induced residual stresses from different machining modes and their repeatability}

Figure 17 highlights that higher feeds result in a higher penetration depths of RS profile and in a higher depth of the MaxRS. Only mode 3 shows a perfect square root-shaped profile with pronounced MaxRS at greater depths and less compressive RS near the surface - whereas the MaxRS for lower feeds (mode 1 and 2) are found closer to the surface, with mode 2 having the highest MaxRS. An explanation for those effects is that the increased load on the sample, due to greater uncut chip thickness and material removal rate (see Table 1), leads to larger plastically deformed areas and therefore deeper residual stresses and the shift of the maximum stresses deeper into the workpiece. Once the maximum of stress is at greater depth, the stresses near the surface are lower to remain in mechanical equilibrium (see mode 3 stress Fig.

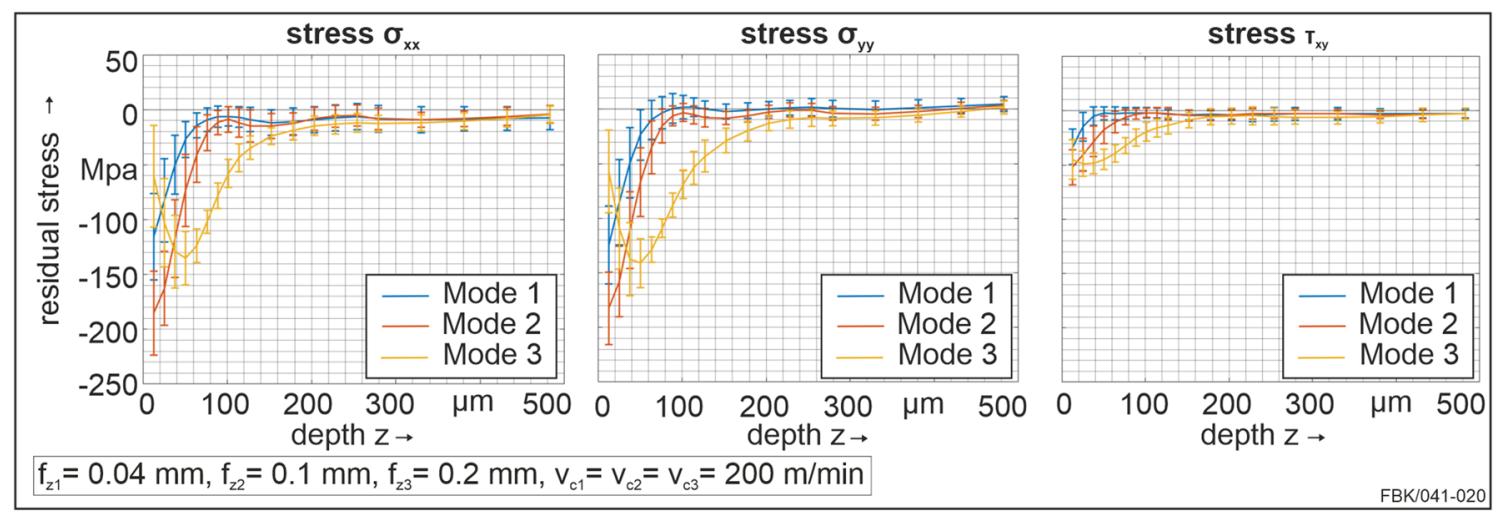

Fig. 17 MIRS inter mode comparison for variation of feed (mode 1, mode 2, mode 3) vise, error bars represent RSTD 


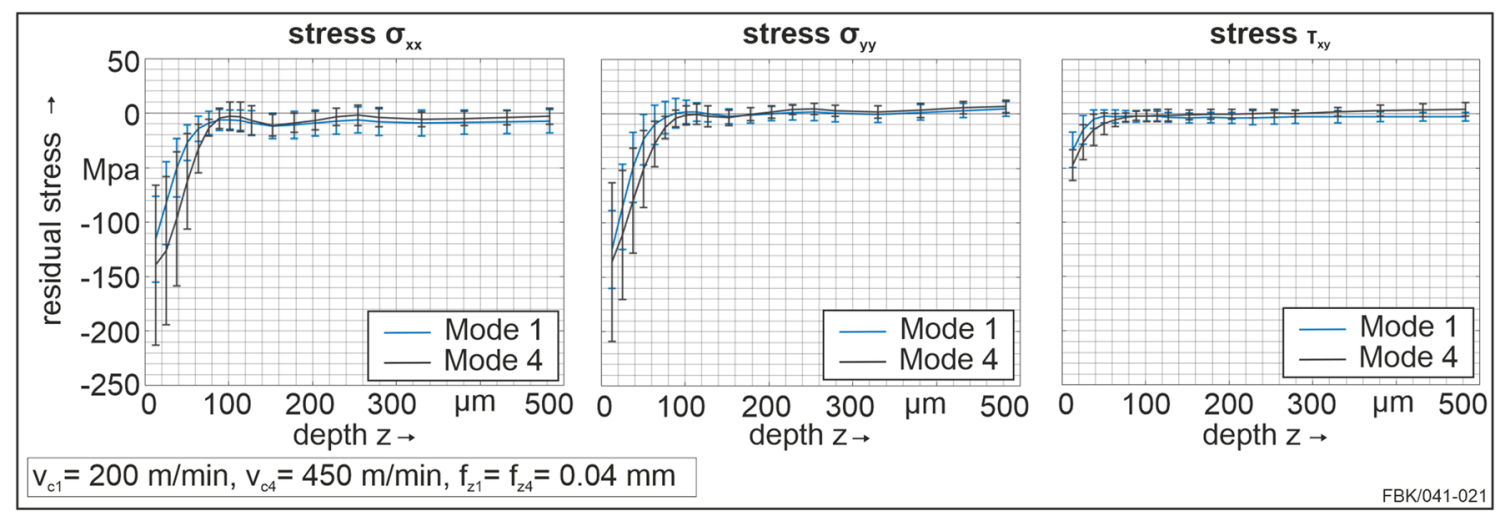

Fig. 18 MIRS inter mode comparison for variation of cutting speed (mode 1, mode 4) vise, error bars represent RSTD

17) [7]. Furthermore, the compressive residual stress distribution results from the combined effect of both competing processes, direct plastic surface deformation and plastic deformation of deeper layers due to Hertzian pressure [26]. It seems that for mode 1 and mode 2 much energy is consumed for direct plastic deformation of the surface, so that the effect of Hertzian pressure cannot be dominant. But here it should be also considered that the measurement technique HD has its highest uncertainty at the first measured depth. Besides, the temperatures do not seem to play a role, since they are on a similar low level $\left(30\right.$ to $55^{\circ} \mathrm{C}$ at a depth of $100 \mu \mathrm{m}$ ) for all three modes (see Fig. 11).

A comparison of the measured RS to the RS due to milling aluminum alloys found in the literature with similar tools shows that a similar RS depth profile with compressive RS in the subsurface and a maximum close to the surface is evident. The measured MaxRS are smaller compared to the ones found in [7] (see Section 1), because different cutting parameters $\left(a_{\mathrm{e}}\right.$ and $\left.a_{\mathrm{p}}\right)$ and tool diameter were used, which also lead to smaller forces compared to the ones shown in [7]. The increased depth of the MaxRS with an increased feed also agrees with findings in [7].

The variation of the cutting speed (see Fig. 18) shows that the average MIRS profiles look similar, although mode 4 shows the most variation, which is indicated by its high standard deviation. This can be explained by the forces, which are similar in their magnitude as well. Furthermore, the temperature experiments showed that there is no big temperature difference for both modes (see Fig. 11). This observation also agrees with similar trends found in the literature [7].

To quantify the repeatability of the MIRS resulting from the four different modes, the average of the MaxRS of each mode and its RSTD and the average of the penetration depth $t_{\mathrm{p}}$ and its RSTD were computed from all 9 MIRS measurements for each mode (see Table 7). As previously described, mode 4 normal stresses show the highest variation, where the RSTD reaches 54\% of the MaxRS. For the other modes, the RSTD is lower (especially for modes 2 and 3 ), where the highest RSTD goes down to $34 \%$ (mode 1), 29\% (mode 2), and 25\% (mode 3 ) of their MaxRS. In the shear direction, mode 1 machining causes the highest variation in $\mathrm{MaxRS}_{\mathrm{xy}}(49 \%)$. In general, it can be seen that the RSTD of the MaxRS increases for lower measured and shallower RS (see Table 7 modes 1 and 4). The measurement technique HD might contribute to this fact, because the qualities to be observed here are close to the limits of the resolution of the observation technique itself [13]. A similar trend is found for the penetration depth $t_{\mathrm{p}}$, where the highest variation shows up for the lowest shear residual stresses (mode 1:52\% and mode 4:41\%). The variation in the depth of the MaxRS $t_{\mathrm{m}}$ seems low for all modes, because for almost all of the MIRS measurements (except mode 3) the MaxRS are found at the first measured depth. It cannot be quantified, because the first measured depth varies (4 to $12 \mu \mathrm{m}$ ) and it is therefore not known at which depth exactly the MaxRS occur.
Table 7 Repeatability standard deviation (RSTD) of MaxRS and penetration depth $t_{\mathrm{p}}$ for all modes

\begin{tabular}{lllll}
\hline & Mode 1 & Mode 2 & Mode 3 & Mode 4 \\
\hline MaxRS $_{\mathrm{x}} \pm \operatorname{RSTD}_{\mathrm{x}}(\mathrm{MPa})$ & $115 \pm 39(34 \%)$ & $185 \pm 39(21 \%)$ & $135 \pm 24(18 \%)$ & $139 \pm 73(53 \%)$ \\
$\operatorname{MaxRS}_{\mathrm{y}} \pm \operatorname{RSTD}_{\mathrm{y}}(\mathrm{MPa})$ & $125 \pm 36(29 \%)$ & $182 \pm 32(18 \%)$ & $141 \pm 23(16 \%)$ & $136 \pm 73(54 \%)$ \\
$\operatorname{MaxRS}_{\mathrm{xy}} \pm \mathrm{RSTD}_{\mathrm{xy}}(\mathrm{MPa})$ & $33 \pm 16(49 \%)$ & $52 \pm 15(29 \%)$ & $49 \pm 12(25 \%)$ & $47 \pm 14(30 \%)$ \\
$t_{\mathrm{px}} \pm t_{\mathrm{p}}-\mathrm{RSTD}_{\mathrm{x}}(\mu \mathrm{m})$ & $56 \pm 22(39 \%)$ & $74 \pm 12(16 \%)$ & $177 \pm 62(35 \%)$ & $62 \pm 18(29 \%)$ \\
$t_{\mathrm{py}} \pm t_{\mathrm{p}}-\mathrm{RSTD}_{\mathrm{x}}(\mu \mathrm{m})$ & $56 \pm 19(34 \%)$ & $70 \pm 11(16 \%)$ & $180 \pm 22(12 \%)$ & $62 \pm 18(29 \%)$ \\
$t_{\mathrm{pxy}} \pm t_{\mathrm{p}}-\operatorname{RSTD}_{\mathrm{xy}}(\mu \mathrm{m})$ & $21 \pm 11(52 \%)$ & $49 \pm 14(29 \%)$ & $105 \pm 26(25 \%)$ & $34 \pm 14(41 \%)$ \\
\hline
\end{tabular}




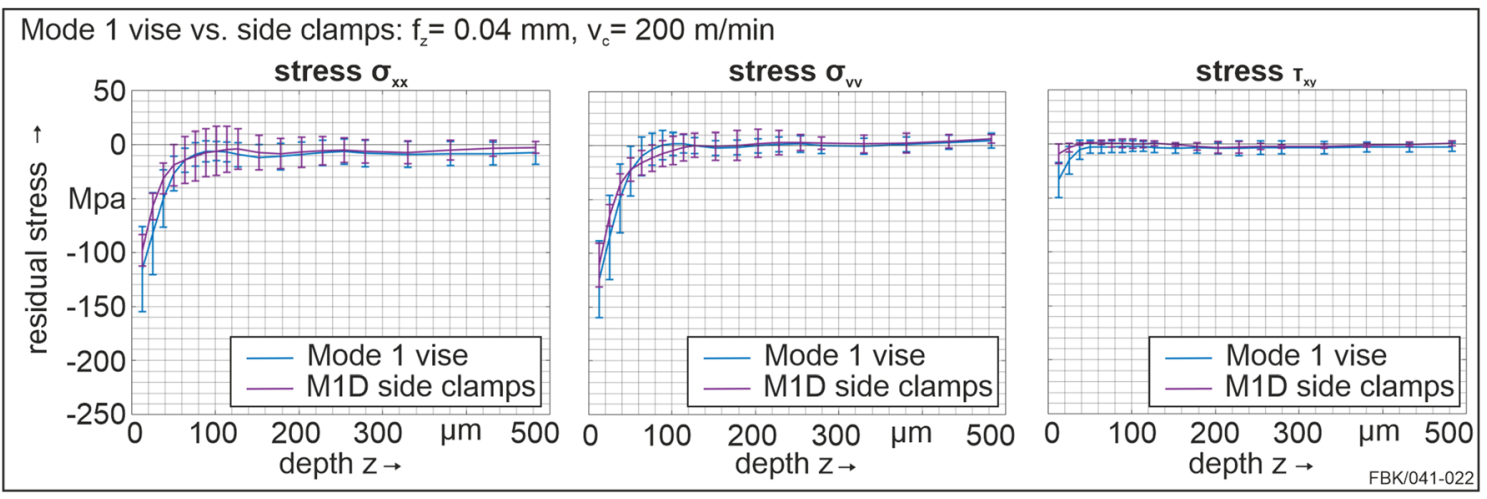

Fig. 19 MIRS mode 1 comparison for vise and side clamps, error bars represent RSTD

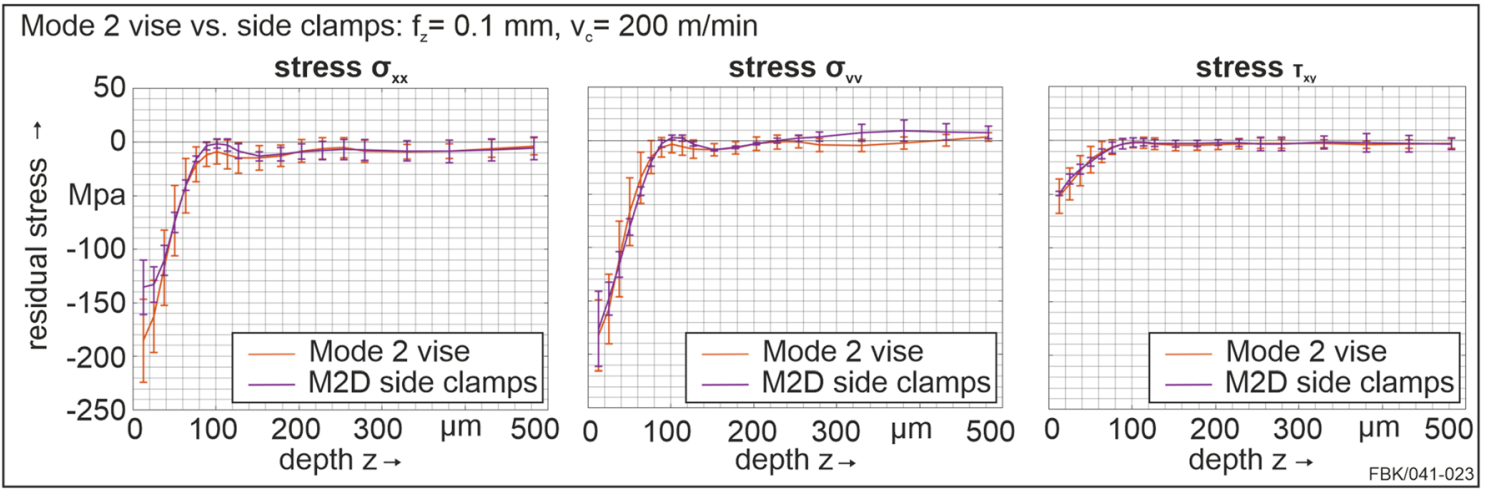

Fig. 20 MIRS mode 2 comparison for vise and side clamps, error bars represent RSTD

However, this is not true for mode 3, where the MaxRS are found at deeper depths. Here a variation of $50 \pm 8 \mu \mathrm{m}(x-$ direction), $52 \pm 6 \mu \mathrm{m}$ (y-direction), and $31 \pm 22 \mu \mathrm{m}$ (shear direction) was found.

\subsubsection{Comparison of MIRS from different clamping strategies}

The comparison of the MIRS profiles of samples machined in the vise and side clamps shows almost no significant differences for mode 1 and mode 2 (see Fig. 19 and Fig. 20). The differences of the MaxRS of the vise and side clamps are quantified by their relative change $\left(\mathrm{MaxRS}_{\text {side clamps }} /\right.$ MaxRS $\left._{\text {vise }}-1\right)$. The change of MaxRS of mode 1 is $-15 \%$ ( $x$-direction), $-11 \%$ ( $y$-direction), and $-62 \%$ ( $x y$-direction). For mode 2, the difference of MaxRS is quantified to $-27 \%$ ( $x$-direction), $-3 \%$ ( $y$-direction), and 5\% ( $x y$-direction). So, the highest differences are found for the $\mathrm{MaxRS}_{\mathrm{x}}$ for mode 2 and the MaxRS $\mathrm{Sy}_{\mathrm{xy}}$ for mode 1. But it has to be considered that their error bars overlap and the MaxRS are at very shallow depths, where the highest uncertainty of the HD technique

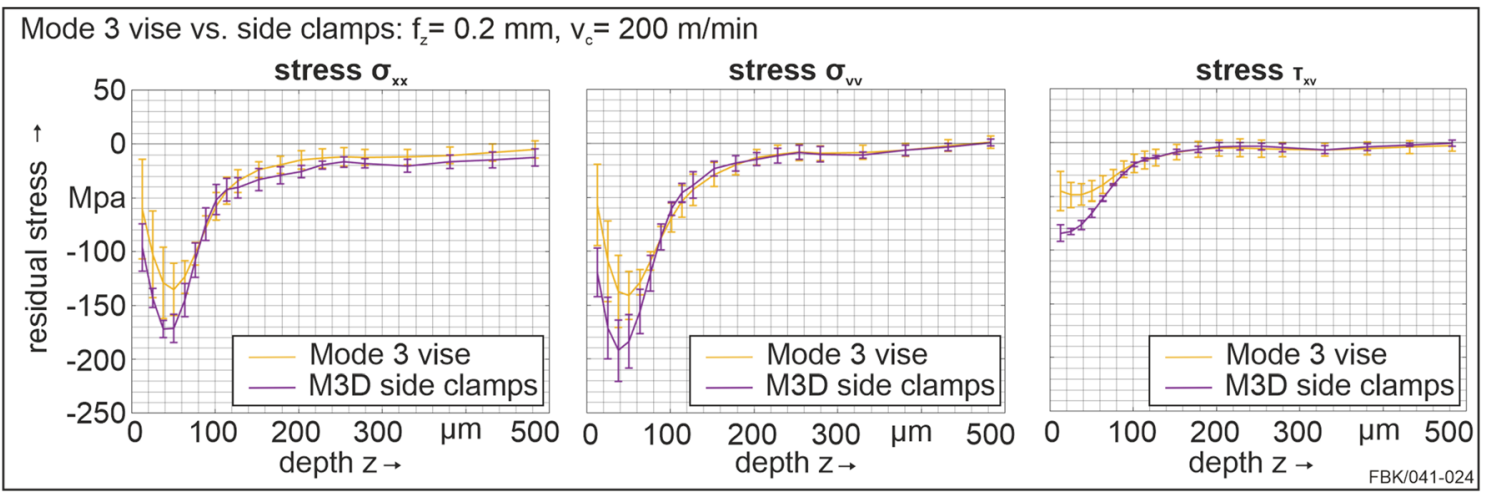

Fig. 21 MIRS mode 3 comparison for vise and side clamps, error bars represent RSTD 


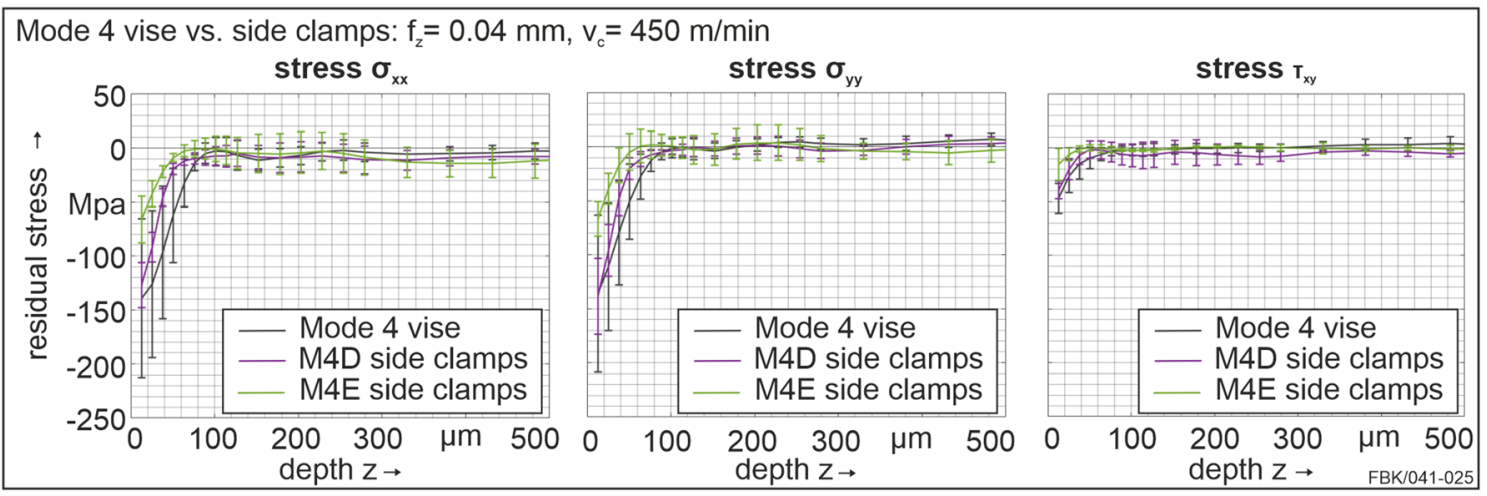

Fig. 22 MIRS mode 4 comparison for vise and side clamps, error bars represent RSTD

takes place. In summary, it can be stated that the RS depth profiles for mode 1 and mode 2 are independent of the two investigated clamping strategies.

Mode 3 stress profiles are also similar with a high repeatability of the penetration depth and the depth of MaxRS (see Fig. 21). The magnitude of compressive RS for the machined sample in side clamps (M3D) seems to be higher than for the samples machined in the vise. But for the normal stresses, it has to be considered that their RSTD lays in each other's range, which means that the difference due to clamping is not statistically significant. The magnitude of shear stress with side clamps is higher than that with the vise and, in contrast, the difference is significant for depth smaller than $80 \mu \mathrm{m}$. The differences of the MaxRS are quantified to $21 \%$ ( $x$-direction), 27\% ( $y$-direction), and 42\% ( $x y$-direction).

A comparison between RS of mode 4 samples which are machined in the vise and side clamps is difficult because, as was stated earlier, the RS resulting from machining of samples clamped in the vise have high variability. Therefore, two instead of one sample were machined in the side clamps (M4D, $\mathrm{M} 4 \mathrm{E})$ to analyze if this condition depends on the clamping device or not. Figure 22 highlights that the stress profile of $\mathrm{M} 4 \mathrm{E}$ is shallower for all three stress components compared to M4D. The error bars of M4D and M4E do not touch each other for shallow depth smaller than $90 \mu \mathrm{m}$. A comparison to the stresses resulting from samples machined in the vise (mode 4 vise) shows that the values of M4D are within the standard deviation from the average mode 4 vise stresses. The differences of the MaxRS are quantified to $-51 \%$ ( $x$-direction), $-50 \%$ ( $y$-direction), and $-64 \%$ ( $x y$-direction) by using the average of the MaxRS of the two samples clamped in side clamps and comparing it to the average MaxRS of the samples machined in the vise. A closer look at the force signals of M4D and M4E reveals that the vibrations have not improved (see Fig. 10). Mode 4 remains still as an unstable machining independent of the fixture.

In general, the stress profiles of the samples machined in the side clamps are similar to the ones machined in the vise.
The clamping behavior in terms of clamping forces and

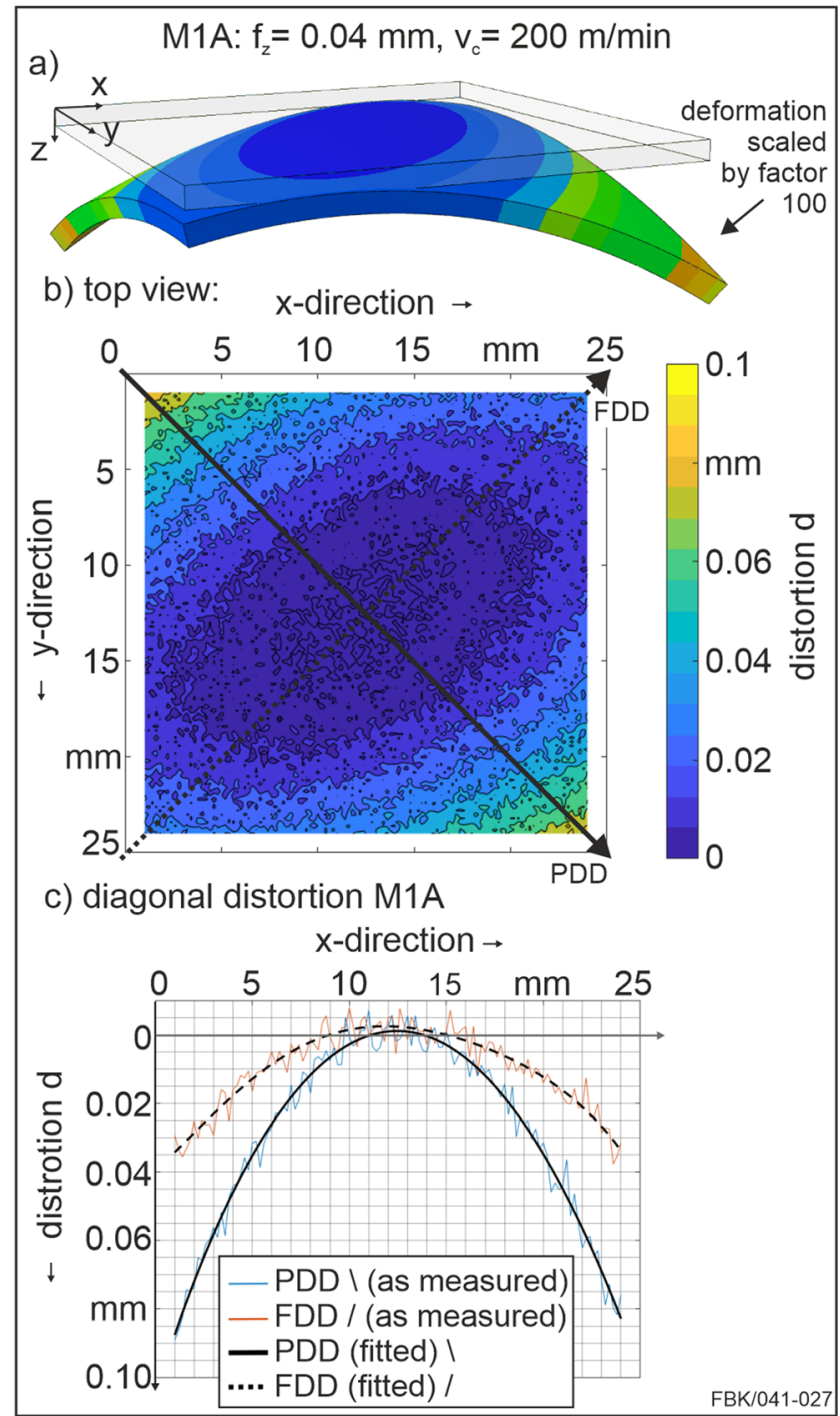

Fig. 23 Qualitative shape of wafer distortion (a), contour plot (b), and diagonal distortions of M1A (c) 
Table 8 Wafer experimental maximum distortion

\begin{tabular}{|c|c|c|c|c|c|c|c|c|}
\hline \multirow{2}{*}{$\begin{array}{l}\text { Mode ( } x \text {-position of } \\
\text { measured edges) } \\
\text { Sample ID }\end{array}$} & \multicolumn{2}{|c|}{$\begin{array}{l}\text { Mode } 1\left(x_{1}=2.6 \mathrm{~mm}\right. \\
\left.\text { and } x_{2}=22.4 \mathrm{~mm}\right)\end{array}$} & \multicolumn{2}{|c|}{$\begin{array}{l}\text { Mode } 2\left(x_{1}=1 \mathrm{~mm}\right. \\
\left.\text { and } x_{2}=24 \mathrm{~mm}\right)\end{array}$} & \multicolumn{2}{|c|}{$\begin{array}{l}\text { Mode } 3\left(x_{1}=2.4 \mathrm{~mm}\right. \\
\left.\text { and } x_{2}=22.6 \mathrm{~mm}\right)\end{array}$} & \multicolumn{2}{|c|}{$\begin{array}{l}\text { Mode } 4\left(x_{1}=1 \mathrm{~mm}\right. \\
\left.\text { and } x_{2}=24 \mathrm{~mm}\right)\end{array}$} \\
\hline & M1A & M1B & M2A & $\mathrm{M} 2 \mathrm{C}$ & $\mathrm{M} 3 \mathrm{C}$ & M3B & M4B & M4A \\
\hline $\mathrm{PDD}_{\max }(\mathrm{mm})$ & 0.062 & 0.045 & 0.14 & 0.116 & 0.152 & 0.116 & 0.123 & 0.047 \\
\hline $\mathrm{FDD}_{\max }(\mathrm{mm})$ & 0.024 & 0.02 & 0.056 & 0.032 & 0.032 & 0.025 & 0.028 & 0.014 \\
\hline Ratio $\mathrm{PDD}_{\max }$ & $73 \%$ & & $83 \%$ & & $76 \%$ & & $38 \%$ & \\
\hline Ratio FDD $_{\max }$ & $83 \%$ & & $57 \%$ & & $78 \%$ & & $50 \%$ & \\
\hline
\end{tabular}

stiffness of the system is similar and does not significantly influence the MIRS.

\subsection{Wafer analysis}

The wafer experiments are designed to show the distortion potential due to the MIRS. It is investigated whether those differences detected in the measured stress profiles cause different machining-induced distortions. Furthermore, the distortion due to the different machining modes is compared. In addition, the numerical FEM simulations analyze whether those measured stresses are consistent with the measured distortion (see Section 3.4.2).

\subsubsection{Comparison of experimental data}

Figure 23 shows the measured wafer distortion M1A (mode 1) as an example. Here, the distortion is defined as the out-ofplane ( $x y$-plane) displacement of the wafer. The machined surface becomes convex ( $\cap$-shaped) due to the compressive

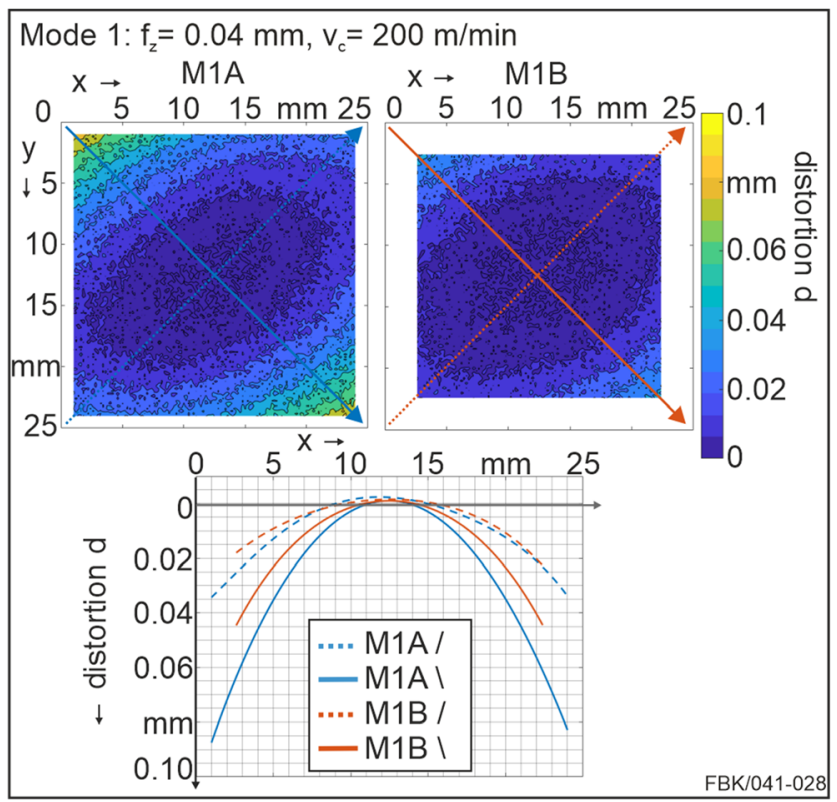

Fig. 24 Mode 1 wafer M1A and M1B distortion
MIRS at the top milled surface (see Fig. 23a). The color map in Fig. 23b mimics looking down at the milled surface with positive distortion in the $z$-direction (into the surface). Its maximum distortion is found at the top left $(0 \mathrm{~mm}, 0 \mathrm{~mm})$ and bottom right corner ( $25 \mathrm{~mm}, 25 \mathrm{~mm})$, because the shear stresses cause a torsional moment in addition to the bending moment induced by the normal RS $[13,28]$. Therefore, the shear stress is responsible for the diagonal orientation of the maximum distortion. In order to compare the distortion of different samples, the distortions along the diagonal lines, top left $(0$ $\mathrm{mm}, 0 \mathrm{~mm}$ ) to bottom right corner $(25 \mathrm{~mm}, 25 \mathrm{~mm})$ (peak distortion diagonal (PDD)) and bottom left $(0 \mathrm{~mm}, 25 \mathrm{~mm})$ to top right (25 mm, $0 \mathrm{~mm}$ ) (flat distortion diagonal (FDD)), are plotted (see Fig. 23c). A polynomial fit of order 5 is applied to the data to smooth it.

Furthermore, the maxima for the PDD and the FDD of different wafers are compared. The distortion value at each corner is computed and averaged for the peak distortion corners $\left(\mathrm{PDD}_{\max }\right)$ and the flat distortion corners $\left(\mathrm{FDD}_{\max }\right)$ respectively (see Table 8). The ratio of $\mathrm{PDD}_{\max }$ (or $\mathrm{FDD}_{\max }$ ) of two different wafers shows how close their distortion is (e.g., $\mathrm{PDD}_{\max } \mathrm{M} 1 \mathrm{~A} / \mathrm{PDD}_{\max } \mathrm{M1B}$ ). Here, $100 \%$ means that their maximum magnitude of distortion at the specific corners is the same. It should be noted that for samples M1B and M3B the analysis space of $23 \times 23 \mathrm{~mm}^{2}$ was trimmed due to measurement errors close to the edges of the wafers.

The distortions of the mode 1 wafers M1A and M1B are compared in Fig. 24. It can be seen that the distortion shape of both wafers is the same convex shape as discussed previously. The distortion of M1B is smaller than M1A, which can be seen clearly from both diagonal line distortion plots (see Fig. 24). The average maximum distortion of the M1B PDD is $73 \%$ of M1A and $83 \%$ for the averaged maximum of the FDD (see Table 8). This behavior can be explained by the differences detected in the MIRS profiles (see Section 3 MIRS analysis). M1B has shallower MIRS with less MaxRS (in all directions) and penetration depth $t_{\mathrm{p}}$ compared to M1A (see Fig. 13).

The same trend occurs for wafers $\mathrm{M} 2 \mathrm{~A}$ and $\mathrm{M} 2 \mathrm{C}$, both machined with mode 2 . The one cut out of the sample with shallower MIRS measured shows less distortion (see Fig. 25 and compare Fig. 14). The average maximum distortion of the 


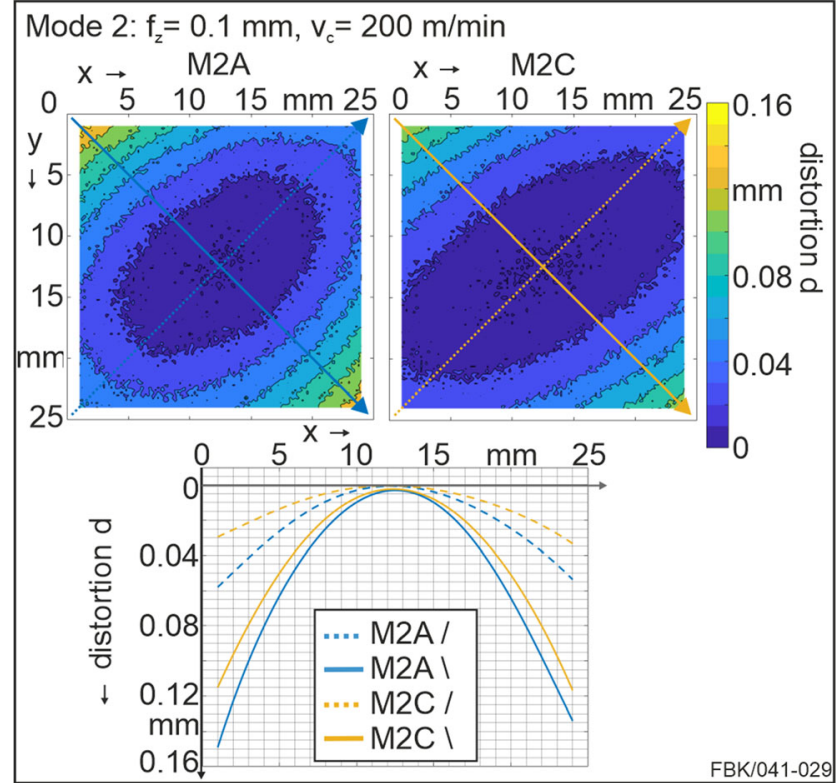

Fig. 25 Mode 2 wafer M2A and M2C distortion

$\mathrm{PDD}$ of $\mathrm{M} 2 \mathrm{C}$ is $83 \%$ of M2A and $57 \%$ for the averaged maximum of the FDD (see Table 8).

The distortion shape of the mode 3 wafers M3B and M3C is also convex (see Fig. 26). It can be seen that their distortion is consistent. The average maximum distortion of the PDD of $\mathrm{M} 3 \mathrm{~B}$ matches the one of M3C by $76 \%$. The averaged maximum of the FDD of M3B accounts for 78\% of M3C's FDD (see Table 8). M3B has less MaxRS (in all directions) than M3C (see Fig. 15), which also results in a lower distortion.

The distortions of the mode 4 wafers M4A and M4B show the same convex shape with their maximum distortion at the

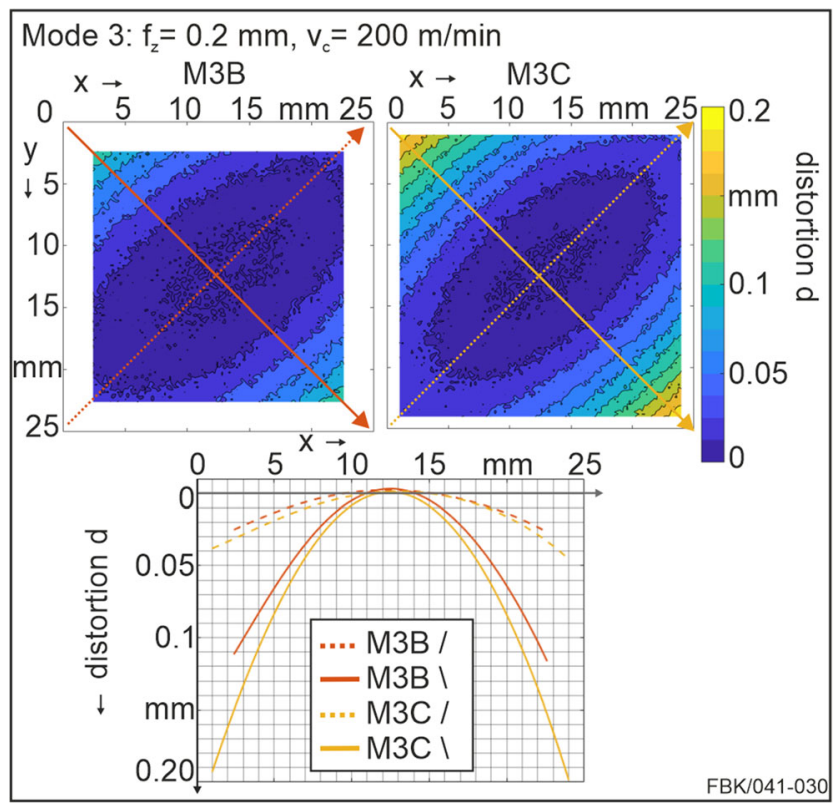

Fig. 26 Mode 3 wafer M3B and M3C distortion corners $(0,0)$ and $(25,25)$ (see Fig. 27). It can be seen that the distortion of M4A is significantly smaller than that of M4B. The average maximum distortion of the M4A PDD is $38 \%$ of M4B and 50\% for the averaged maximum of the FDD (see Table 8). This is due to the differences in MIRS (see Section 3 MIRS analysis). M4A has significant shallower MIRS with less MaxRS (in all directions) compared to M4B (see Fig. 16).

In summary, small differences in MIRS for modes 1,2, and 3 result in small changes in their distortion. Big differences in mode 4 MIRS also lead to big differences in distortion of mode 4 wafers. Furthermore, Fig. 28a shows that with increasing feed the maximum distortion increases. The distortion of the opposite diagonal, the flat distortion, does not show this trend, because of the high normal stresses of mode 2 compared to mode 3 (compare Fig. 17). The comparison of the variation in cutting speed shows no clear trend, because mode 4 has such big variations in MIRS and distortions (Fig. 28b). In general, it can be stated that the MIRS and the wafer distortion are related, with more and/or deeper compressive RS causing more distortion.

\subsubsection{FEM wafer distortion analysis}

Figure 29 shows the distortion of mode $1 \mathrm{M} 1 \mathrm{~A}$ and M1B wafers and the simulated distortions due to the measured MIRS from M1A (averaged three measurements) and M1B respectively, as contour plots and their diagonal distortions. The distortions of simulation and experiment of M1A match. Both show the previously described convex-shaped distortion on a similar level, but the experimental data is more twisted than the simulation. This indicates that shear stresses used for

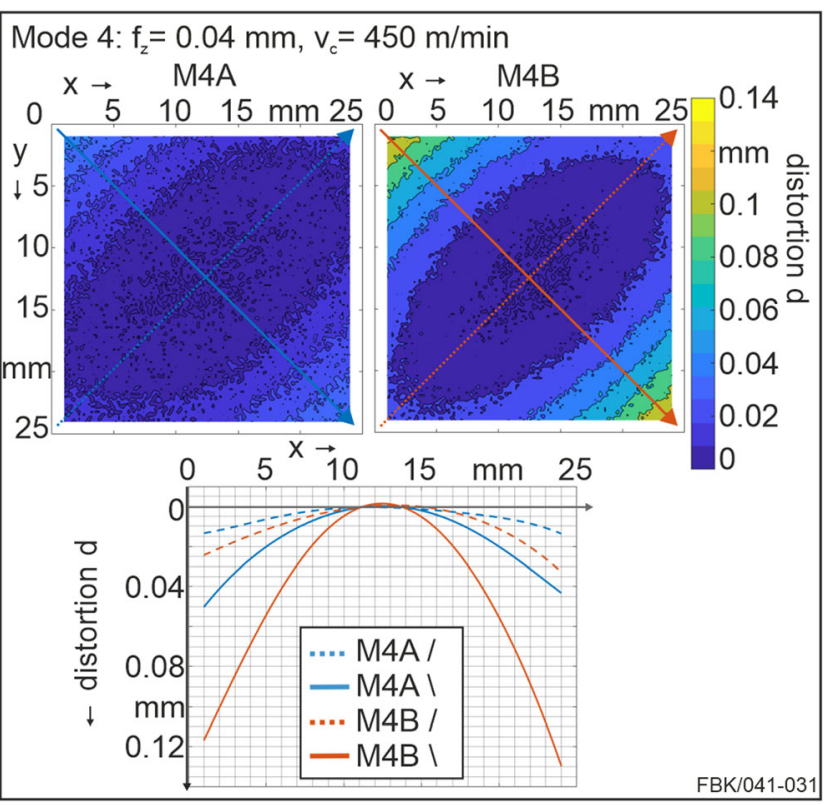

Fig. 27 Mode 4 wafer M4A and M4B distortion 


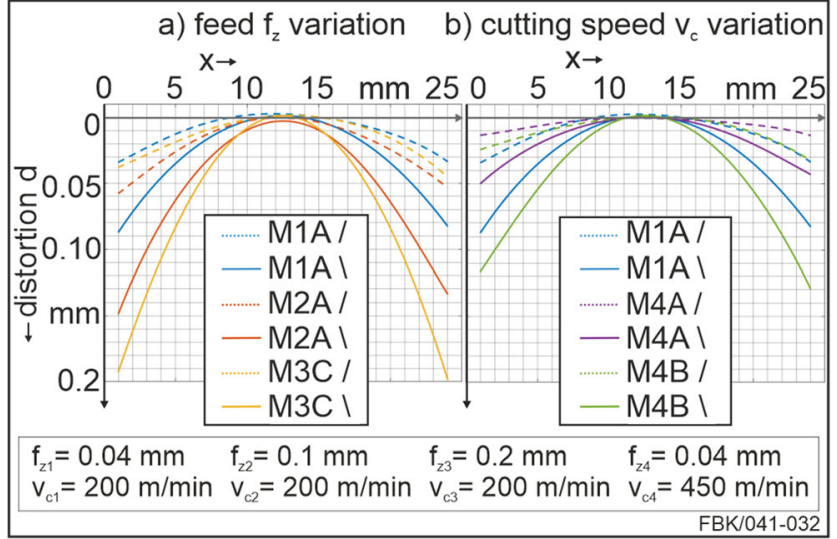

Fig. 28 Inter mode comparison of wafer distortion for feed variation (a) and cutting speed variation (b)

the simulation are not fully correct. The line plots show that the real distortion is bigger than the simulated one. Table 9 highlights that the experimental averaged maximum distortion of the PDD (FDD) of M1A is reached by the simulation up to $75 \%(65 \%)$. A similar behavior is visible for M1B. But here the simulated shape differs in a way that the FDD shows almost no bending. This indicates that the MIRS used for the simulation were not fully correct, which is also suggested by the higher RSTD of the M1B MIRS (see Fig. 13). However, the PDD reaches $76 \%$ of the measured data.

The distortions of the mode 2 wafers M2A and M2C are consistent with their simulated distortion, calculated with the average of the three measured MIRS profiles of M2A and $\mathrm{M} 2 \mathrm{C}$ respectively (see Fig. 30). Its convex distorted shape is similar and the magnitude of distortion is at a similar level.
The simulated averaged maximum distortion accounts for $91 \%$ (M2A) and 76\% (M2C) of the experimental averaged maximum distortion $\mathrm{PDD}_{\max }$ (see Table 9). The $\mathrm{FDD}_{\max }$ shows $45 \%$ (M2A) and 83\% (M2C) agreement between the simulation and measured averaged maximum flat distortion.

The measured distortions of the mode 3 wafers M3B and $\mathrm{M} 3 \mathrm{C}$ and their simulated distortion (input: average of three measurements on M3B, M3C respectively) are displayed in Fig. 31. It can be seen that the measured and simulated shapes of distortion agree well. The distortions of the PDD and the FDD show small differences in magnitude. The simulation gets as close as $91 \%$ (M3B) and $82 \%$ (M3C) of the experimental $\mathrm{PDD}_{\max }$ data (see Table 9). Only $31 \%$ (M3B) and $43 \%$ $(\mathrm{M} 3 \mathrm{C})$ are reached for $\mathrm{FDD}_{\max }$.

The distortion of the mode 4 wafer M4B is consistent with its simulated distortion due to the measured MIRS (average of three measurements on M4B) (see Fig. 32). The prediction of the wafer distortion shape M4A agrees to a certain point, whereas the bending in the FDD direction is not fully achieved similar to M1B distortion prediction. The reason is that the MIRS of the input are not fully correct, because MIRS are really low with higher variability. Furthermore, as discussed in the previous section, the level of distortion of both samples (M4A and M4B, mind different scales in Fig. 32) varies accordingly to their induced RS. The model is able to predict those different levels of distortion. The peak corner distortions $\mathrm{PDD}_{\max }$ are reached by $77 \%$ (M4A) and $67 \%$ (M4B) by the simulation. Twenty-nine percent (M4A) and 96\% (M4B) of the $\mathrm{FDD}_{\text {max }}$ data are reached by the simulation (see Table 9).

In general, the finite element simulations show that the measured MIRS are consistent with the measured distortion for different machining parameters, because the overall distorted shapes of experiment and simulation match for each wafer. The magnitude of measured and simulated distortion of

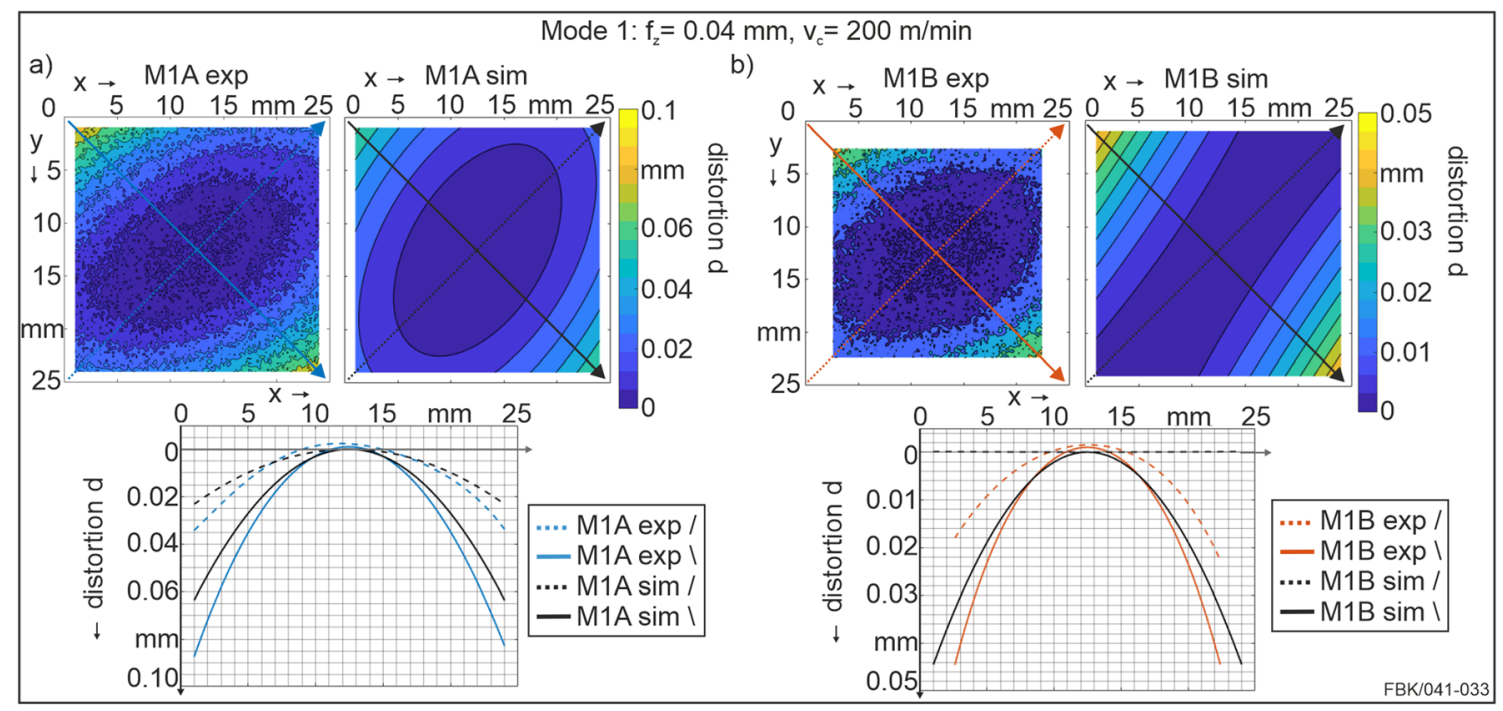

Fig. 29 Wafer mode 1 measured and simulated distortion of M1A (a) and M1B (b); mind different scales 
each wafer is on the same level, but, e.g., the highest distortions found vary down to $67 \%$ (peak line distortion). Especially for really low MIRS (see M1A, M1B, and M4A), the biggest differences between model and wafer measurements are found, because those low MIRS showed the highest variability themselves. For higher distortions due to higher MIRS, an agreement up to $91 \%$ of $\mathrm{PDD}_{\max }$ (M2A, M3B) is found. Furthermore, the distortion in the peak diagonal direction is simulated to a higher accuracy than that in the opposite direction. One reason for the differences in the magnitude of distortion could be that the MIRS are only measured to a depth of approximately $500 \mu \mathrm{m}$. Although a stress relief process was carried out after heat treatment and before machining, there is still a small amount of IBRS up to $20 \mathrm{MPa}$ left [16], which is neglected by the simulation. Moreover, the already mentioned uncertainties of the measuring technique itself, especially at shallow depths, contribute to the difference in distortion of simulation and experiment. Besides, there could be RS induced by the EDM cutting, although the cutting parameters were chosen to minimize the stress induced during cutting.

However, it was found that variations of MIRS within one machining mode result in a variation of distortion in a way that is consistent as determined via the model.

\section{Conclusions and outlook}

An overall repeatability of measured RS and forces for modes 1,2 , and 3 has been proven and the two investigated clamping strategies (vise and side clamps) have almost no impact for those modes on the MIRS. E.g., the differences of the MaxRS in normal direction were stated to a maximum of $15 \%$ (M1) and 27\% (M2 and M3). The repeatability standard deviation for those modes machined in the vise lays in the normal directions between 16 and 34\% of the maximum normal compressive residual stresses. Furthermore, it was found that the repeatability standard deviation of the maximum shear stress was the highest for machining mode $1(49 \%)$ inducing least shear residual stresses. A similar behavior was detected for the penetration depth of the MIRS, where the highest RSTD was reached by mode 1 in shear direction (52\% of $t_{\mathrm{pxy}}$ ). Those detected variations in the MIRS profiles within machining modes 1, 2, and 3 also lead to small deviations in the wafer distortion.

Mode 4 showed more variability compared to other modes for the vise and side clamps, because machining for mode 4 was not stable. The RSTD of the MaxRS was greater than for the other modes in normal directions (53\% of the MaxRS $\mathrm{S}_{\mathrm{x}}$ and $54 \%$ MaxRS $_{\mathrm{y}}$.). Vibrations were detected in the force signal of $F_{\mathrm{z}}$. The big differences in MIRS also resulted in big (compared to other modes) differences in the machining-induced distortion. 


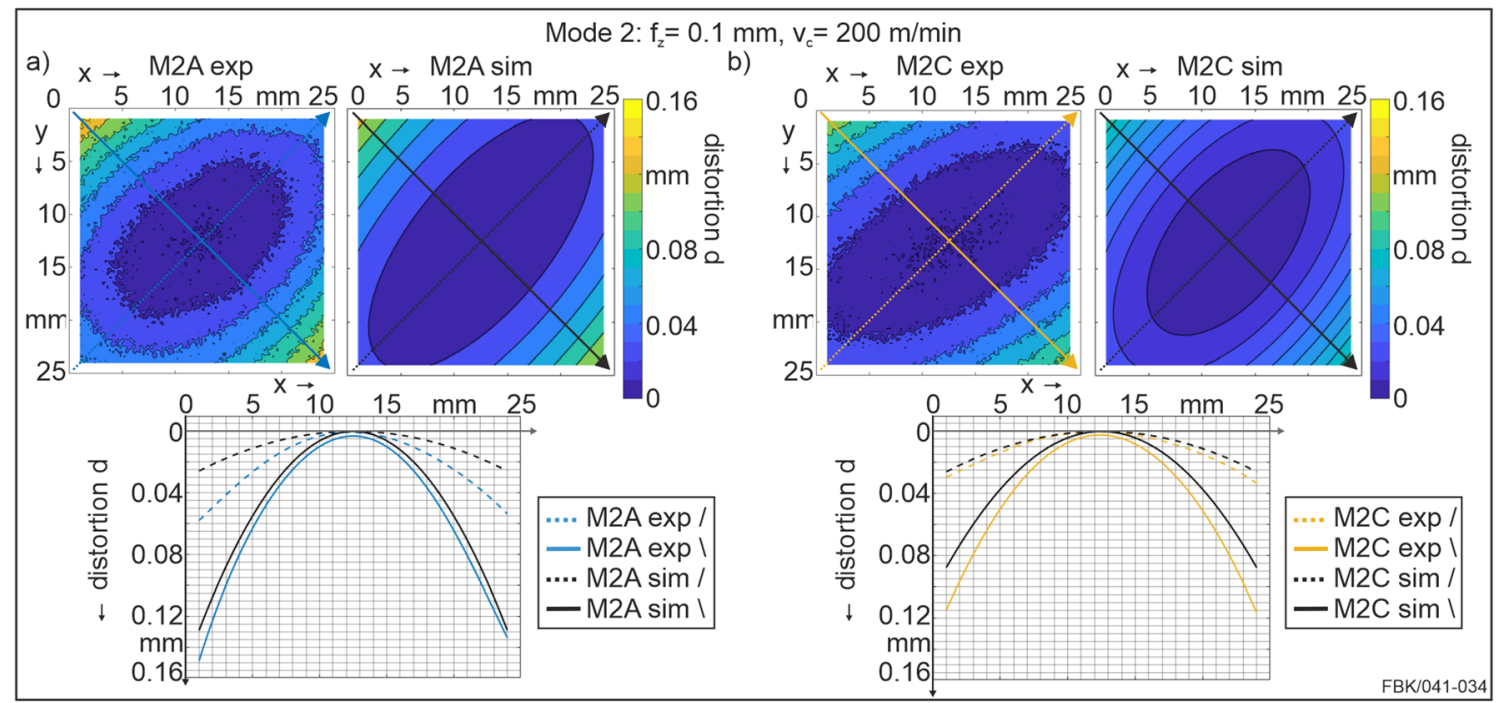

Fig. 30 Wafer mode 2 measured and simulated distortion of M2A (a) and M2C (b)

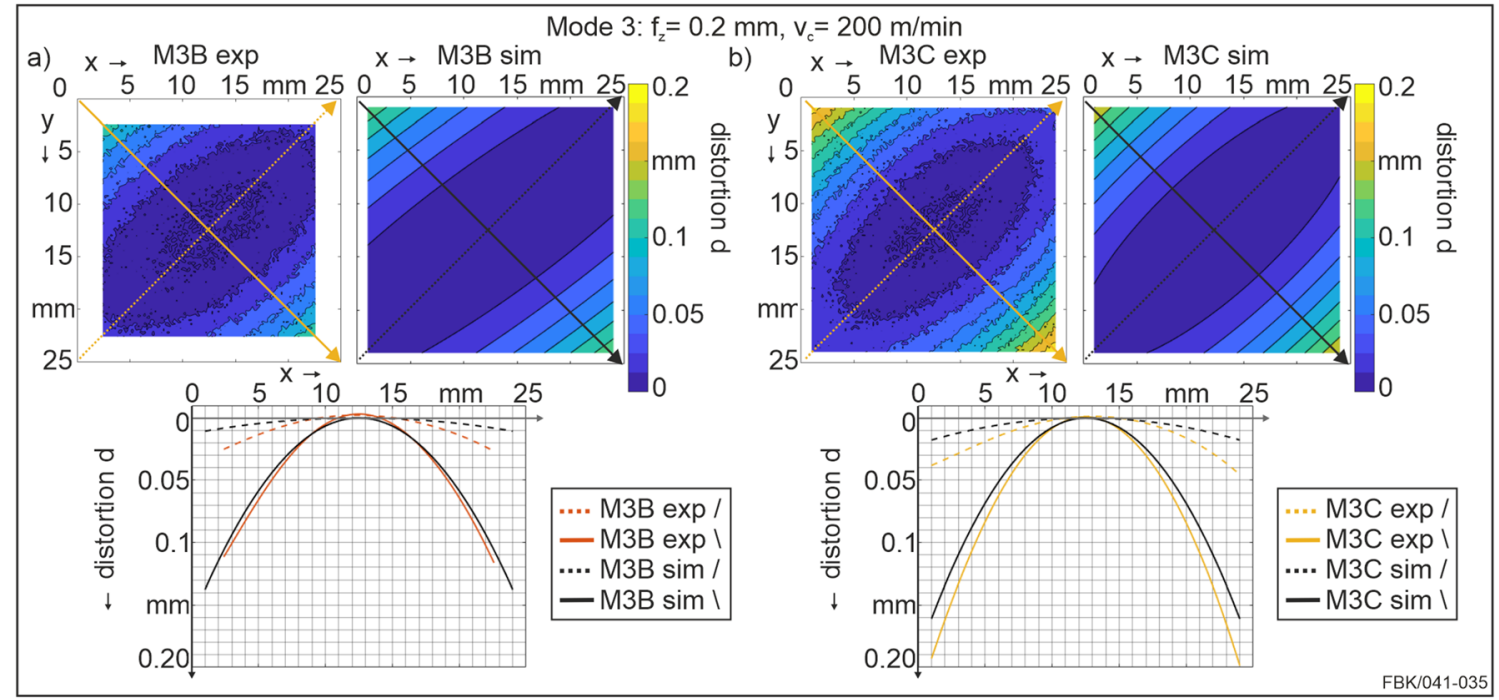

Fig. 31 Wafer mode 3 measured and simulated distortion of M3B (a) and M3C (b)

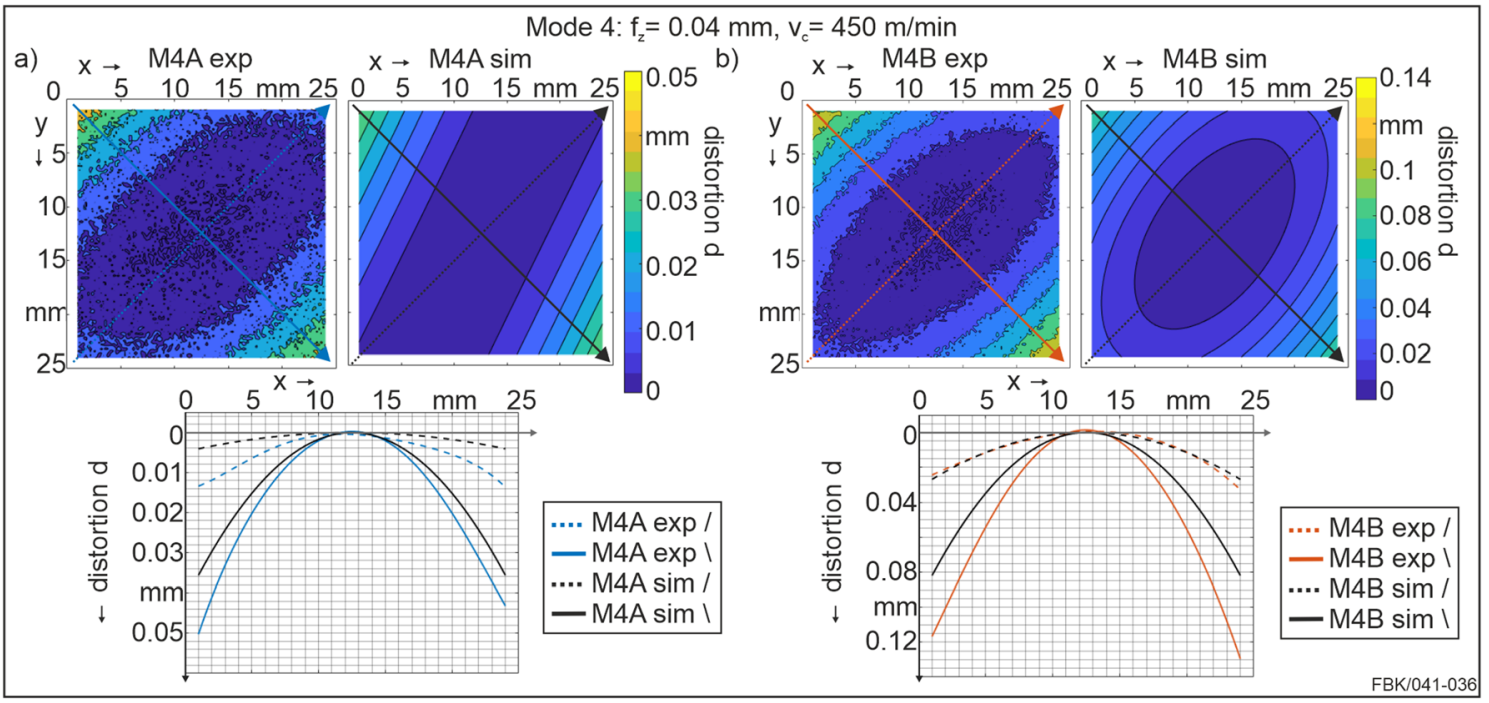

Fig. 32 Wafer mode 4 measured and simulated distortion of M4A (a) and M4B (b); mind different scales 
The variation of feed per tooth showed that higher feeds result in a higher penetration depth of RS profile and in a higher depth of the maximum compressive RS due to the increased load on the sample, which leads to larger plastically deformed areas and therefore deeper residual stresses and the shift of the maximum stresses deeper into the workpiece. These stresses also lead to an increased machining-induced distortion with increased feeds. The variation of the cutting speed showed in average, although mode 4 had the highest variation itself, similar MIRS profiles due to similar forces and temperatures prevailing during machining. In order to see an effect of an increased cutting speed on the MIRS, higher cutting speeds are needed.

Furthermore, the numerical stress analysis showed that the measured distortion across all machining modes is a machining-induced distortion. The MIRS and the distortion behave related in a way that more and/or deeper compressive RS cause more distortion. It was found that variations of MIRS within one machining mode result in a variation of distortion in a way that is consistent as determined via the model. Besides, the shear stresses are essential and responsible for a torsional moment, which contributes highly to the shape and maximum of distortion.

\section{Author contribution Not applicable}

Funding Open Access funding enabled and organized by Projekt DEAL. The work presented in the paper was funded by the German Research Foundation (DFG) and the National Science Foundation (NSF) within the project AU 185/64-1 "NSF DFG Collaboration to Understand the Prime Factors Driving Distortion in Milled Aluminum Workpieces" (NSF funding Award No. 1663341). UC Davis received funding from the National Science Foundation under Award No. 1663341 (Division of Civil, Mechanical and Manufacturing Innovation (CMMI)).

Data availability Data and material are stored at TU Kaiserslautern and UC Davis.

Code availability (software application or custom code) The commercial software ABAQUS was used to run the distortion simulations.

\section{Declarations}

Conflict of interest The authors declare no competing interests.

Disclaimer Any opinions, findings, and conclusions or recommendations expressed in this material are those of the authors and do not necessarily reflect the views of the National Science Foundation or the Deutsche Forschungsgemeinschaft.

Open Access This article is licensed under a Creative Commons Attribution 4.0 International License, which permits use, sharing, adaptation, distribution and reproduction in any medium or format, as long as you give appropriate credit to the original author(s) and the source, provide a link to the Creative Commons licence, and indicate if changes were made. The images or other third party material in this article are included in the article's Creative Commons licence, unless indicated otherwise in a credit line to the material. If material is not included in the article's Creative Commons licence and your intended use is not permitted by statutory regulation or exceeds the permitted use, you will need to obtain permission directly from the copyright holder. To view a copy of this licence, visit http://creativecommons.org/licenses/by/4.0/.

\section{References}

1. Cai XJ, Ming WW, Chen M (2012) Surface integrity analysis on high speed end milling of 7075 aluminum alloy. Adv Mater. Res 426:321-324. https://doi.org/10.4028/www.scientific.net/AMR. 426.321

2. Jawahir IS, Brinksmeier E, M'Saoubi R, Aspinwall DK, Outeiro JC, Meyer D, Umbrello D, Jayal AD (2011) Surface. Integrity in Material Removal Processes: Recent Advances CIRP Annals Manufacturing Technology 60(2):603-626. https://doi.org/10. 1016/j.cirp.2011.05.002

3. Perez I, Madariaga A, Cuesta M, A. Gray A, Arrazola PJ, Ruiz JJ, Rubio FJ, Sanchez R (2018) Effect of cutting speed on the surface integrity of face milled 7050-T7451 aluminium workpieces. Procedia CIRP 71 - Proceedings to the 4th CIRP Conference on Surface Integrity:460-465. https://doi.org/10.1016/j.procir.2018. 05.034

4. Sim WM (2010) Challenges of residual stress and part distortion in the civil airframe industry. Int J Micro-struct Mater Prop 5:446455. https://doi.org/10.1504/IJMMP.2010.037621

5. Li J, Wang S (2016) Distortion caused by residual stresses in machining aeronautical aluminum alloy parts: recent advances. Int $\mathrm{J}$ Adv Manuf Technol 89(1-4):997-1012. https://doi.org/10.1007/ s00170-016-9066-6

6. Masoudi S, Amini S, Saeidi E, Eslami-Chalander H (2015) Effect of machining-induced residual stress on the distortion of thinwalled parts. Int J of Adv Manuf Technol 76:597-608. https://doi. org/10.1007/s00170-014-6281-x

7. Denkena B, Boehnke D, de Leon L (2008) Machining induced residual stress in structural aluminum parts. Production Engineering 2:247-253. https://doi.org/10.1007/s11740-0080097-1

8. Denkena B, Reichstein M, de Leon GL (2008) Milling Induced Residual Stresses in Structural Parts out of Forged Aluminum Alloys. Int J Mach And Machinab of Mater 4(4):335-344. https:// doi.org/10.1504/IJMMM.2008.023717

9. Rao B, Shin Y (2001) Analysis on high-speed face-milling of 7075T6 aluminum using carbide and diamond cutters. Int J of Mach Tools \& Manuf 41:1763-1781. https://doi.org/10.1016/S08906955(01)00033-5

10. Huang X, Sun J, Li j, Han X (2013) An Experimental Investigation of Residual Stresses in High-Speed End Milling 7050-T7451 Aluminum Alloy. Adv in Mech Eng. https://doi.org/10.1155/ 2013/592659

11. Tang ZT, Liu ZQ, Wan Y (2008) Ai X (2008) Study on Residual Stresses in Milling Aluminium Alloy 7050-T7451. In: Yan X-T, Jiang C, Eynard B (eds) Advanced design and manufacture to gain competitive edge: new manufacturing techniques and their role in improving enterprise performance. Springer, London, pp 169-178

12. Li B, Jiang X, Yang J, Liang SY (2015) Effects of depth of cut on the redistribution of residual stress and distortion during the milling of thin-walled part. J of Mat Process Technol 216:223-233. https:// doi.org/10.1016/j.jmatprotec.2014.09.016

13. Chighizola CR, D'Elia CR, Weber D, Kirsch B, Aurich JC, Linke BS, Hill MR (2021) Intermethod Comparison and Evaluation of 
Near Surface Residual Stress in Milled Aluminum. Submitted and currently under review in Experimental Mechanics 11(2020)

14. Chighizola CR, D'Elia CR, Hill MR (2020) Intermethod comparison and evaluation of near surface residual stress in aluminum parts subject to various milling parameters. In: Baldi A et al (eds) Residual Stress, Thermomechanics \& Infrared Imaging and Inverse Problems, Volume 6. Conference Proceedings of the Society for Experimental Mechanics Series. Springer, Cham. https://doi.org/10.1007/978-3-030-30098-2_10

15. Handbook ASM (1991) Heat Treating of Aluminum Alloys. ASM Handbook 4:841-879. https://doi.org/10.1361/asmhba0001205

16. Prime MB, Hill MR (2002) Residual stress, stress relief, and inhomogeneity in aluminum plate. Scripta Materialia 46(1):77-82. https://doi.org/10.1016/S1359-6462(01)01201-5

17. Weber D, Kirsch B, D'Elia CR, Linke BS, Hill MR, Aurich JC (2019) Concept to analyze residual stresses in milled thin walled monolithic aluminum components and their effect on part distortion. Production at the lead-ing edge of technology - Proceedings of the 9th Congress of the German Academic Association for Production Technology:287-296. https://doi.org/10.1007/978-3662-60417-5 29

18. Garcia DR, Hill MR, Aurich, JC, Linke BS (2017) Characterization of machining distortion due to residual stresses in quenched aluminium. In 12th Int. Manuf. Science and Engineering Conference (1), MSEC2017-2878

19. Denkena B, Dreier S (2014) Simulation of residual stress related part distortion. In New Production Technologies in Aerospace Industry - Proceedings of the 4th Machining Innovations Conference: $105-113$.

20. Jayanti S, Ren D, Erickson E, Usui S, Marusich T, Marusich K, Elanvogan H (2013) Predictive modeling for tool deflection andpart distortion of large machined components. In Procedia CIRP 12 Proceedings of the 8th CIRP Conference on Intelligent Computation in Manufacturing Engineering:37-42.
21. Richter-Trummer V, Koch D, Witte A, dos Sanos JF, de Castro PMST (2013) Methodology for prediction of distortion of workpieces manufactured by high speed machining based on an accurate through-the-thickness residual stress determination. Int $\mathrm{J}$ of $\mathrm{Adv}$ Manuf Tech 68:2271-2281

22. Bi Y, Cheng Q, Dong H, Ke Y (2009) Machining distortion prediction of aerospace monolithic components. J Zhejiang Univ Sci A 10(5):2 661-668.

23. ASTM International (2013) E837-13a Standard Test Method for Determining Residual Stresses by the Hole-Drilling Strain-Gage Method. West Conshohocken, PA: ASTM International. https:// doi.org/10.1520/E0837-13A

24. Grant P, Lord J, Whitehead P, Fry AT (2005) The Application of Fine Increment Hole Drilling for Measuring Machining-Induced Residual Stresses. Applied Mechanics and Materials 3-4:105-110. https://doi.org/10.4028/www.scientific.net/AMM.3-4.105

25. Klocke F (2011) Manufacturing Processes 1. Springer, Berlin

26. Wohlfahrt H (1984) The influence of peening conditions on the resulting distribution of residual stress. Proc. Of the 2th Intern. Conf. on Shot Peening:316-331.

27. Dassault Systems (2016). Simulia ABAQUS 2016 Abaqus Analysis User's Guide: 34.2.1 Initial conditions in Abaqus/ Standard and Abaqus/Explicit.

28. Gulpak M, Sölter J, Brinksmeier E (2013). Prediction of shape deviations in face milling of steel. In Procedia CIRP 8 Proceedings of the 14th CIRP Conference on Modelling of Machining Operations:15-20. doi:https://doi.org/10.1016/j.procir. 2013.06.058.

Publisher's note Springer Nature remains neutral with regard to jurisdictional claims in published maps and institutional affiliations. 